\title{
ATM mutations and E-cadherin expression define sensitivity to EGFR-targeted therapy in colorectal cancer
}

\author{
Anna-Lena Geißler ${ }^{1,2,3,4}$, Miriam Geißler ${ }^{1,2,3}$, Daniel Kottmann ${ }^{1,2,3}$, Lisa Lutz $^{1,2}$, \\ Christiane D. Fichter ${ }^{1,2,3}$, Ralph Fritsch ${ }^{2,5,7}$, Britta Weddeling ${ }^{1,7}$, Frank Makowiec ${ }^{2,6,7}$, \\ Martin Werner ${ }^{1,2,4,7}$, Silke Lassmann ${ }^{1,2,4,7,8}$ \\ ${ }^{1}$ Institute of Surgical Pathology, University of Freiburg, Freiburg im Breisgau, Germany \\ ${ }^{2}$ Faculty of Medicine, University of Freiburg, Freiburg im Breisgau, Germany \\ ${ }^{3}$ Faculty of Biology, University of Freiburg, Freiburg im Breisgau, Germany \\ ${ }^{4}$ German Cancer Consortium (DKTK) and German Cancer Research Center (DKFZ), Heidelberg, Germany \\ ${ }^{5}$ Department of Internal Medicine, University of Freiburg, Freiburg im Breisgau, Germany \\ ${ }^{6}$ Department of Surgery, University of Freiburg, Freiburg im Breisgau, Germany \\ ${ }^{7}$ Comprehensive Cancer Center Freiburg, All Medical Center - University of Freiburg, Freiburg im Breisgau, Germany \\ ${ }^{8}$ BIOSS Centre for Biological Signaling Studies, University of Freiburg, Freiburg im Breisgau, Germany \\ Correspondence to: Silke Lassmann, email: silke.lassmann@uniklinik-freiburg.de \\ Keywords: anti-EGFR therapy, next generation sequencing, predictive markers, colorectal cancer (CRC), E-cadherin \\ Received: July 11, 2016 \\ Accepted: January 16, 2017 \\ Published: February 09, 2017
}

\section{ABSTRACT}

EGFR-targeted therapy is a key treatment approach in patients with RAS wildtype metastatic colorectal cancers (CRC). Still, also RAS wildtype CRC may be resistant to EGFR-targeted therapy, with few predictive markers available for improved stratification of patients. Here, we investigated response of 7 CRC cell lines (Caco2, DLD1, HCT116, HT29, LS174T, RKO, SW480) to Cetuximab and correlated this to NGS-based mutation profiles, EGFR promoter methylation and EGFR expression status as well as to E-cadherin expression. Moreover, tissue specimens of primary and/or recurrent tumors as well as liver and/or lung metastases of 25 CRC patients having received Cetuximab and/or Panitumumab were examined for the same molecular markers. In vitro and in situ analyses showed that EGFR promoter methylation and EGFR expression as well as the MSI and or CIMP-type status did not guide treatment responses. In fact, EGFR-targeted treatment responses were also observed in RAS exon 2 p.G13 mutated CRC cell lines or CRC cases and were further linked to PIK3CA exon 9 mutations. In contrast, non-response to EGFR-targeted treatment was associated with ATM mutations and low E-cadherin expression. Moreover, down-regulation of E-cadherin by SiRNA in otherwise Cetuximab responding E-cadherin positive cells abrogated their response. Hence, we here identify ATM and E-cadherin expression as potential novel supportive predictive markers for EGFR-targeted therapy.

\section{INTRODUCTION}

Colorectal cancer (CRC) is the third most common cancer and the third leading cause of cancer death in both men and women [1]. Although death rates are declining due to early detection programs, improved treatment strategies for metastatic CRC are still emerging. Surgical resection and/or chemotherapy based on capecitabine, irinotecan, oxaliplatin, fluorouracil, leucovorin and targeting drugs like bevacizumab are a current standard therapeutic option [2]. Moreover, monoclonal antibodies (mAbs) targeting the epidermal growth factor receptor (EGFR), namely Cetuximab and Panitumumab, have been approved for the metastatic situation. These therapeutic mAbs bind to the extracellular domain of EGFR and inhibit downstream signaling of the RAS/MAPK and $\mathrm{PI} 3 \mathrm{~K} / \mathrm{AKT}$ pathways, which promote (cancer) cell proliferation, survival and growth. Resistance to EGFRtargeting mAbs exists in CRC patients, whose tumors harbor an EGFR downstream activating KRAS or NRAS 
mutation. Hence, RAS mutation testing is a routine diagnostic molecular pathology pre-requisite for clinical decision making on EGFR-targeted therapy, as laid out in clinical guidelines [3]. Still, 40-60\% of CRC patients with RAS wild type tumors do not benefit from EGFR-targeted mAbs [4] and predictive markers for this subgroup of $\mathrm{CRC}$ patients are lacking. Since EGFR-targeted therapy is mostly in combination with chemotherapy (e.g. FOLFOX treatment regimen), not only EGFR-associated, but also other cellular signaling pathways and processes may confer resistance and define novel predictive markers.

Indeed, predictive markers further to RAS were first suggested to be found within the EGFR downstream signaling pathways, including alterations of - for example - BRAF, PIK3CA and PTEN [5, 6]. Of these, PIK3CA and associated kinases - as key regulators of the PI3K/ AKT pathway - are highly attractive predictive and, in fact, also potentially actionable candidates: PIK3CA is a proto-oncogene encoding phosphatidylinositol 3-kinase (PI3K), the signal inducer of the PI3K-AKT pathway and is mutated in about $10-30 \%$ of CRC, mostly in sequence hotspots in exons 9 and 20 [7, 8]. It is predictive for inhibition by combined Dabrafenib/Trametinib treatment [9] and is itself targetable by novel agents.

Nevertheless, predictive markers for CRC patients scheduled for or undergoing EGFR-targeted (chemotherapy-combined) therapy may also reside within the cellular mechanisms of cell damage. As such, ataxiatelangiectasia mutated (ATM) is a serine/threonine protein kinase belonging to the PI3K family. It functions as a key mediator of DNA damage response and induces cell cycle arrest [10]. Furthermore, inhibitors against ATM are in preclinical development and a radiosensitizing effect was reported, particularly in cells defective in p53 [11]. Both, ATM and TP53 are frequently mutated in cancers of the colon and rectum [12], but their predictive value for RAS wildtype CRC patients treated by EGFR-targeted therapy in combination with chemotherapy still has to be elucidated.

Irrespective of these "downstream" mechanisms of treatment resistance and potential predictive markers, few studies have (re-)evaluated alterations within the actual target structure - EGFR - and/or its altered expression or functionality. Hence, in contrast to the prediction of treatment responses to HER2-targeted mAb therapy in breast cancer [13], EGFR protein expression analysis or its regulation at the DNA level are not in the focus of treatment prediction of response to EGFR-targeted therapy in CRC patients. Moreover, the role of crosstalk of EGFR with other cellular pathways and/or induced EGFR bypass signaling via e.g. other membrane receptors [14] remains unclear.

With the increasing knowledge about epigenetic regulation of cancers, methylation of $\mathrm{CpG}$ sites within promoter regions may be an attractive monitor of gene repression and protein expression [15]. So far, few studies have addressed the role of EGFR methylation status as a predictive marker for EGFR-targeted treatment responses beyond the key predictive markers addressing gene mutations and yielded conflicting results: Scartozzi [16] described a better overall survival in patients without EGFR promoter methylation, whereas Chiadini [17] reported an improved response and overall survival in patients with $\geq 10 \%$ EGFR methylation.

Protein expression and/or activity of EGFR thereby also response to EGFR-targeted therapies - may also be regulated by other means, for example E-cadherin: E-cadherin is a transmembrane protein, playing a role in cell adhesion and the maintenance of epithelial cell integrity, which is altered upon metastasis [18]. E-cadherin is known to be lost in epithelial cancers during epithelial to mesenchymal transition (EMT) and metastasis [19], such as in CRC [20] and non-small-cell lung cancers [21]. Interestingly, in an experimental model system, soluble E-cadherin was induced by MMP9 activity and - in its soluble form - was able to actually activate EGFR [22]. Thus, the observed "loss" of E-cadherin - as detected by immunohistochemistry in most studies so far - may in fact indicate the induction of a soluble E-cadherin form, which interacts with and activates EGFR, thereby possibly leading to treatment resistance. Indeed, correlation of E-cadherin protein expression in CRC $[23,24]$, NSCLC [25] and urothelial [26] cancer cells with response to EGFR-targeted therapy showed that E-cadherin "loss" (with possible induction of soluble E-cadherin) points towards EGFR-targeted treatment resistance.

In the present study, we therefore assessed broad mutation profiles, EGFR methylation and expression as well as E-cadherin expression as predictive markers in $7 \mathrm{CRC}$ cell lines treated by EGFR-targeted mAb in vitro as well as in a cohort of 25 clinically RAS wildtype CRC patients having been treated by EGFR-targeted therapy. We identify mutations in DNA damage response associated genes and E-cadherin expression as potential supportive predictive markers for EGFR-targeted therapy of RAS wildtype CRC.

\section{RESULTS}

\section{Sensitivity of CRC cell lines to Cetuximab}

To establish in vitro correlates for EGFR-targeted therapy responses observed in CRC patients, we first measured the effect of Cetuximab on cell viability of seven colorectal cancer (CRC) cell lines. Of these, 3/7 cell lines are KRAS and NRAS wild type (Caco-2, HT29 and RKO) and 4/7 cell lines are KRAS mutated (DLD1, HCT116, LS174T and SW480). In addition, 3/7 cell lines are microsatellite stable (Caco-2, HT29, SW480) and 4/7 are microsatellite instable (DLD1, HCT116, LS174T, RKO) [27]. For further molecular classification, $\mathrm{CpG}$ island methylator phenotype (CIMP) status determination 
Table 1: KRAS, BRAF PIK3CA and ATM mutations of 7 CRC cell lines

\begin{tabular}{lcccc}
\hline Cell line & Cetuximab response & KRAS & BRAF & PIK3CA \\
\hline DLD1 & +++ & p.Gly13Asp & p.Glu545Lys \\
HCT116 & ++ & p.Gly13Asp & p.Asp549Asn \\
LS174T & ++ & p.Gly12Asp & p.His1047Arg \\
SW480 & - & p.Gly12Val & p.Arg2461Pro \\
Caco-2 & ++ & & & \\
HT29 & ++ & & p.Val600Glu & p.Pro872Ser \\
RKO & - & p.Val600Glu & p.His1047Arg \\
\hline
\end{tabular}

revealed CIMP positivity for $4 / 7$ cell lines (DLD1, HCT116, HT29 and RKO) and CIMP negativity for 3/7 cell lines (Caco-2, LS174T and SW480).

As expected for $\mathrm{mAb}$-based treatment in vitro, mere incubation of CRC cells with different concentrations of Cetuximab $(0.1,1,10,50$ and $100 \mu \mathrm{g} / \mathrm{ml})$ had almost no effect on cell viability in any of the investigated CRC cell lines. In this setting, the strongest response was a 20\% loss of cell viability in exclusively LS174T cells (Figure 1A).

We therefore next investigated the response of the seven CRC cell lines to Cetuximab by antibody-dependent cellular cytotoxicity (ADCC) $[28,29]$. Indeed, upon coculture with increasing numbers of effector cells, three distinct patterns of response to Cetuximab were observed in the seven CRC cell lines (Figure 1B): Cetuximab was most effective in DLD1 cells, followed by intermediate responses in HT29, HCT116, LS174T and Caco-2 cells, whereas RKO and SW480 cells were non-responsive to Cetuximab treatment at all effector-target ratios. Thereby, the cell line responses to Cetuximab were not directly linked to RAS mutation status, with responding cells either being RAS mutated (DLD1, HCT116, LS147T) or not (Caco-2, HT29). Vice-versa, non-responding cells were either RAS mutated (SW480) or not (RKO).

Hence, the selected CRC cell lines are a model for EGFR-targeted treatment by mAbs in vitro and - as seen in CRC patients - their RAS mutation status does not appear to be the single predictive marker for treatment response to EGFR-targeted mAb therapy.
A

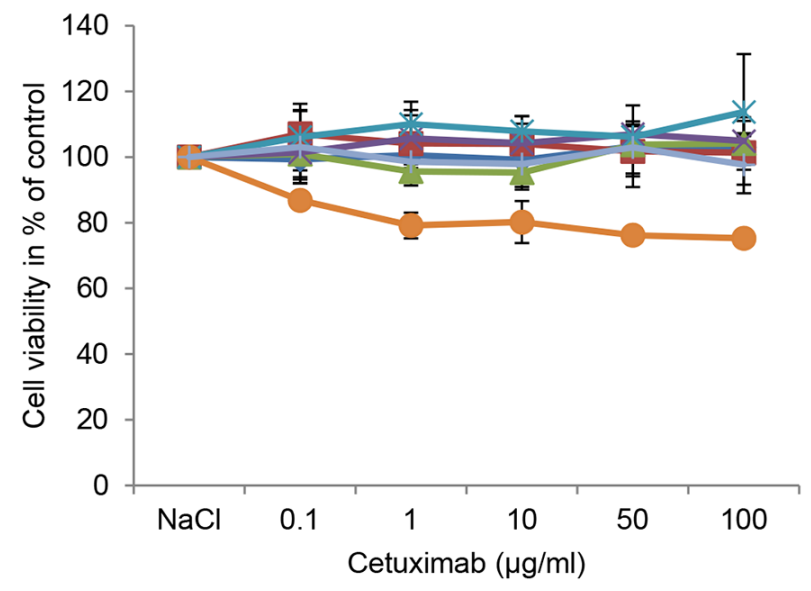

B

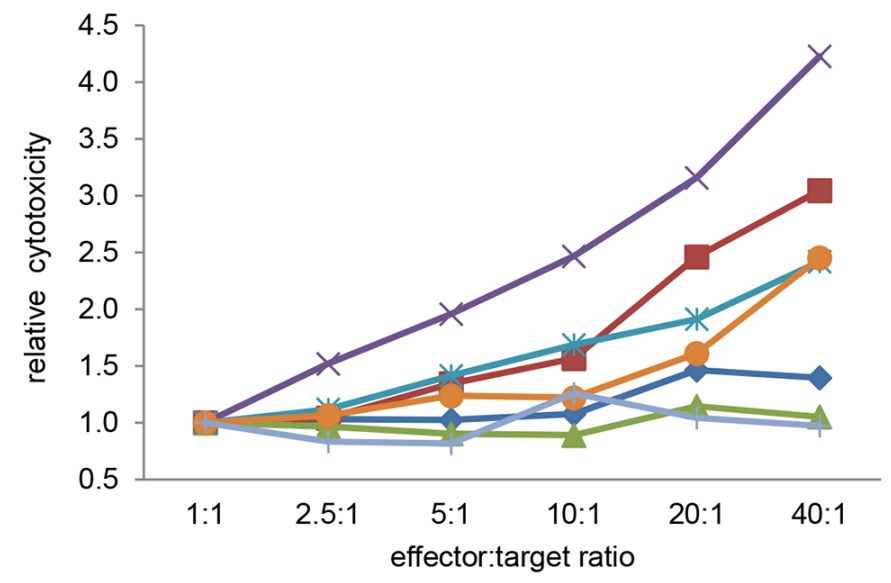

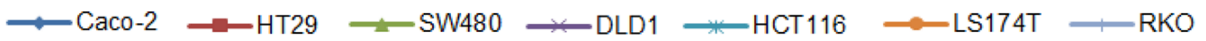

Figure 1: Cetuximab elicits antibody-dependent cellular cytotoxicity in CRC cell lines. A. Three KRAS wild type (Caco2, HT29, RKO) and four KRAS mutant cell lines (SW480, DLD1, HCT116, LS174T) were treated with increasing concentrations of Cetuximab $(0.1,1,10,50,100 \mu \mathrm{g} / \mathrm{ml})$ for $72 \mathrm{~h}$. Cell viability was measured using MTS assay. Cell viability is illustrated in \% of control cells $(0.9 \% \mathrm{NaCl})$. Values shown are the mean of $\mathrm{n}=3$ independent experiments. B. Antibody dependent cellular cytotoxicity (ADCC) measured after co-cultivation of increasing numbers of effector cells (peripheral blood mononuclear cells, PBMCs) with target cells (CRC cell lines) for $4 \mathrm{~h}$ in the presence of $10 \mu \mathrm{g} / \mathrm{ml}$ Cetuximab. 


\section{Distinct mutation profiles occur in Cetuximab responding and non-responding CRC cell lines}

Screening for 46 additional genes to KRAS and NRAS by targeted next generation sequencing next defined additional oncogenes and/or tumor suppressor genes related to the observed Cetuximab responses in vitro.

The number of mutated genes in the 7 cell lines ranged from 4 (Caco-2) to 10 (DLD1) (Supplementary Figure 1A). No significant mutation pattern correlating with the cell lines' response or non-response to Cetuximab was detected. However, the resistant cell lines RKO and SW480 both harbored an ATM mutation and no mutations in those genes affected in the responding and intermediate responding CRC cell lines (HNF1A, SMAD4, SMO, ABL, CTNNB1, IDH1, NOTCH1, STK11) (Supplementary Figure 1B). In addition, PIK3CA exon 9 mutations (p.E545K, p.D549N) were detected exclusively in responding DLD1 cells, whereas a PIK3CA exon 20 mutation (p.H1047R) was present in intermediate responding HCT116 and LS174T as well as in nonresponding RKO cell (Table 1).

Finally, all cell lines were screened for the recently described EGFR exon 12 resistance mutation p.S492R, described as occurring during EGFR-treatment [30] by dideoxy sequencing. However, none of the cell lines was positive for this mutation at base-line (Supplementary Figure 1C).

Thus, broader mutation profiles or the number of mutations does not alone define response of CRC cells to Cetuximab in vitro.

\section{Regulation of EGFR expression by EGFR promoter methylation}

To correlate in vitro Cetuximab treatment responses to potential alterations of the target structure, i.e. EGFR itself, EGFR mRNA and protein expression as well as EGFR promoter methylation were assessed in all seven CRC cell lines (Figure 2).

Immunofluorescence revealed strong membranous EGFR protein expression only in Caco-2 cells (Figure 2A). Marginal, mainly cytoplasmic EGFR protein expression was observed in HT29, LS174T and DLD1 cells, whereas the HCT116, RKO and SW480 cells were EGFR negative. These EGFR protein expression patterns correlated to EGFR mRNA expression, which was highest in Caco-2 (13.21 \pm 3.85$)$ cells, followed by HT29 (2.47 \pm 0.23$)$, LS174T

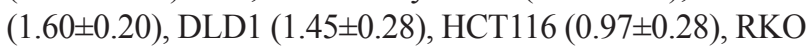
$(0.34 \pm 0.04)$ and SW480 $(0.04 \pm 0.02)$ cells (Figure 2B).

Finally, epigenetic regulation of EGFR expression [31] was examined by EGFR promoter methylation analysis via pyrosequencing. EGFR promoter methylation was lowest in the strong EGFR expressing Caco-2 cells $(6.3 \%)$ and higher (range 60\%-81\%) in all other CRC cell lines (Figure 2C).
Hence, in addition to RAS status also EGFR expression, closely regulated by DNA promoter methylation in Caco-2 cells, does not directly guide the responses of CRC cell lines to Cetuximab.

\section{E-cadherin protein expression differs in Cetuximab responding and non-responding CRC cell lines}

Based on the hypothesis that E-cadherin expression may influence EGFR-targeted treatment responses [2426], we next examined E-cadherin protein expression in all seven CRC cell lines.

As seen by immunofluorescence staining using two E-cadherin antibodies (Figure 3A), strong membranous and in part cytoplasmic E-Cadherin was detectable in DLD1 cells. HT29 and LS174T cells also showed marked fully circular membranous E-cadherin expression, whilst in Caco-2 and HCT116 E-cadherin expression was in part non-membranous and more cytoplasmic in cells without other cell contacts. In RKO and SW480 cells, weak E-cadherin expression was seen. In the latter two cell lines with weak E-cadherin expression as detected by the first antibody (clone NCH-38, DakoCytomation/Agilent, recognizes the $120 \mathrm{kD}$ mature form and a $82 \mathrm{kD}$ (soluble) fragment of E-cadherin), the second antibody (clone 24E10, Cell Signaling Technology, raised against P780 of E-cadherin and stains cytoplasmic E-cadherin) revealed a stronger E-cadherin expression, but predominantly in the cytoplasm. The levels of E-cadherin protein expression were confirmed by western blot analyses using the second antibody, showing lower E-cadherin protein levels in RKO and SW480 (Figure 3B). Moreover, whilst DLD1, HCT116, LS174T and Caco-2 cells expressed both the mature $(120 \mathrm{kDa})$ and immature $(130 \mathrm{kDa})$ E-cadherin protein, this was not the case for HCT116, RKO and SW480 cells.

To investigate soluble levels of E-cadherin, cell culture supernatants of the 7 cell lines were additionally examined by ELISA at 48 and 72 hours (Figure 3C). Thereby, low levels of soluble E-cadherin were detected in RKO and SW480 cells, whilst moderate soluble E-cadherin levels with a slight increase at 72 hours of cultivation were seen in ascending order in HCT116, DLD1, HT29, Caco-2 and LS174T cells.

To further validate that E-cadherin levels have an impact on the response of CRC cells to Cetuximab, DLD1 exhibiting strong E-cadherin protein expression were subjected to control- and E-cadherin-specific siRNA treatment followed by analysis of antibodydependent cellular cytotoxicity. As shown in Figure 4A, E-cadherin protein levels were down-regulated post $72 \mathrm{~h}$ of E-cadherin-specific siRNA treatment, particularly regarding the loss of the $120 \mathrm{kDa}$ mature E-cadherin. Moreover, in DLD1 cells treated by E-cadherin-specific siRNA and Cetuximab, the cell cytotoxicity via ADCC 
A
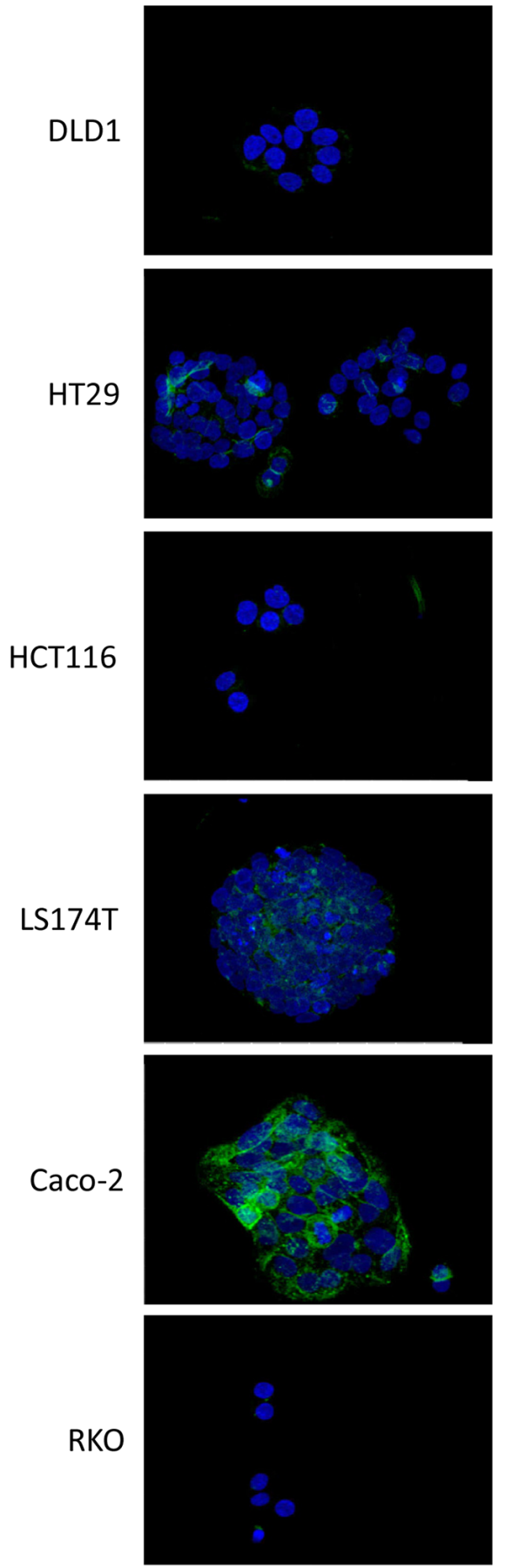

SW480
B

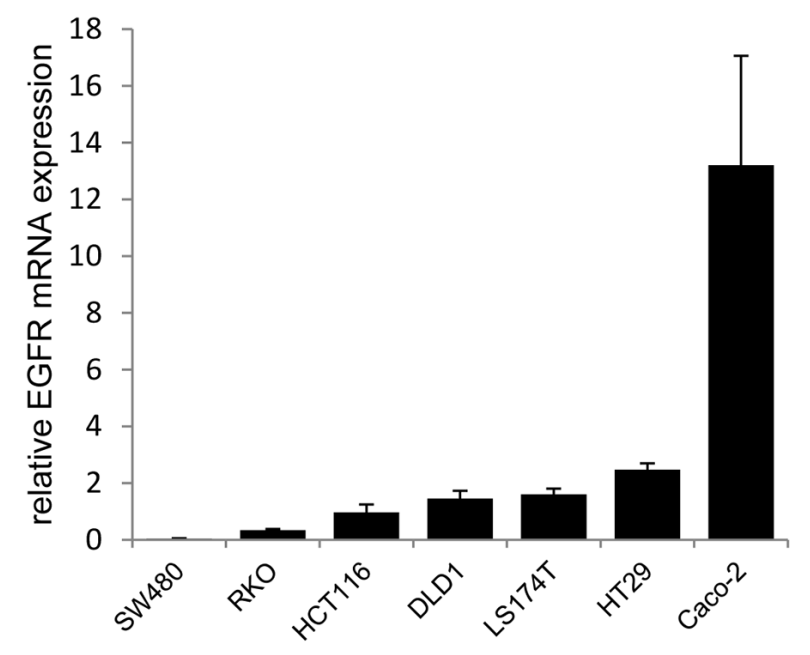

C

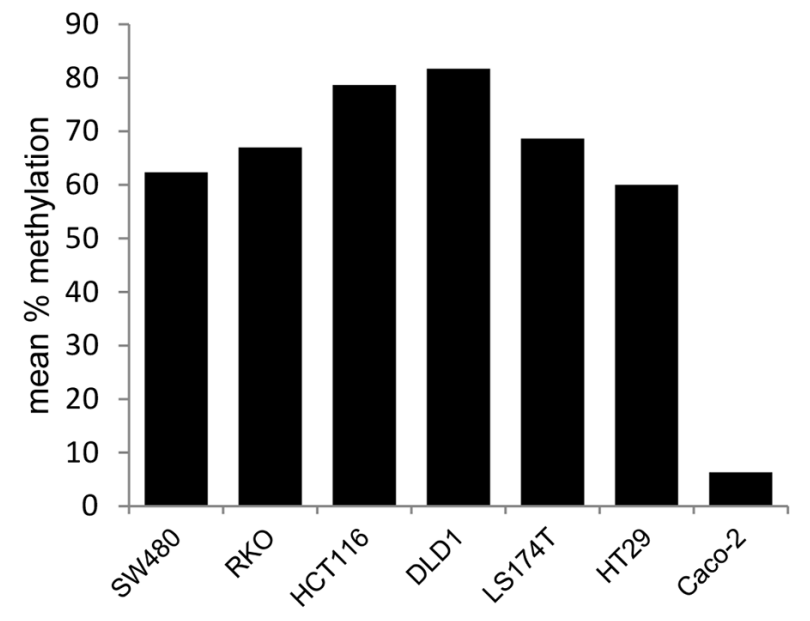

Figure 2: EGFR expression is inversely correlated with EGFR promoter methylation in CRC cell lines. A. Colorectal cancer cell lines (SW480, RKO, HCT116, DLD1, LS174T, HT29 and Caco-2) were stained for EGFR (green) and DAPI for visualization of the nucleus (blue). The representative stainings show a 40x magnification. B. Relative EGFR mRNA expression as determined by q-RT$\mathrm{PCR}$ (mean \pm standard deviation of three independent experiments; relative to a universal reference RNA). C. Mean \% methylation of three CpG sites within the promoter of EGFR. 
A
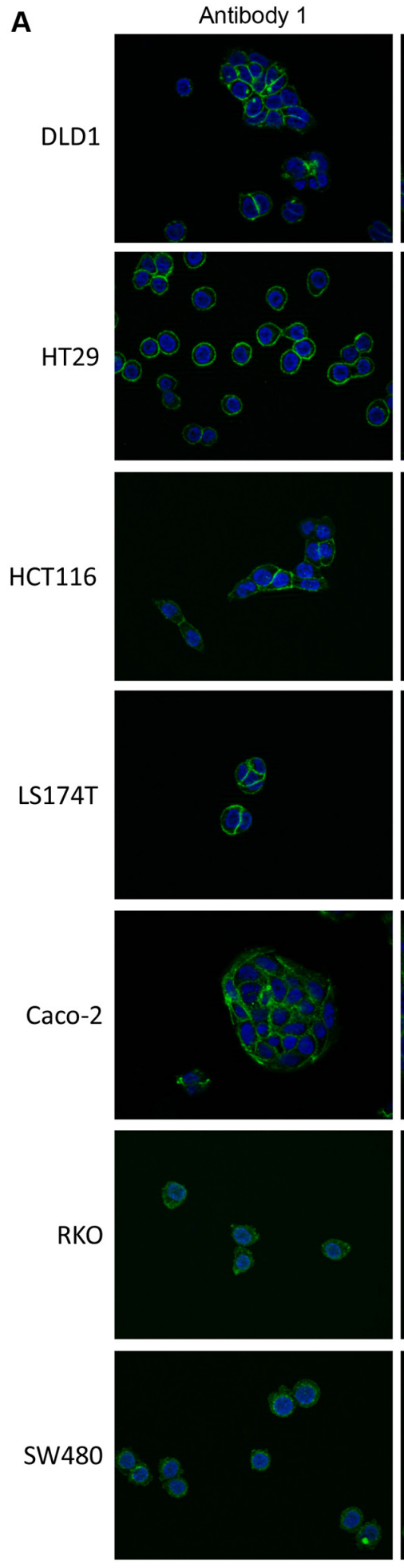
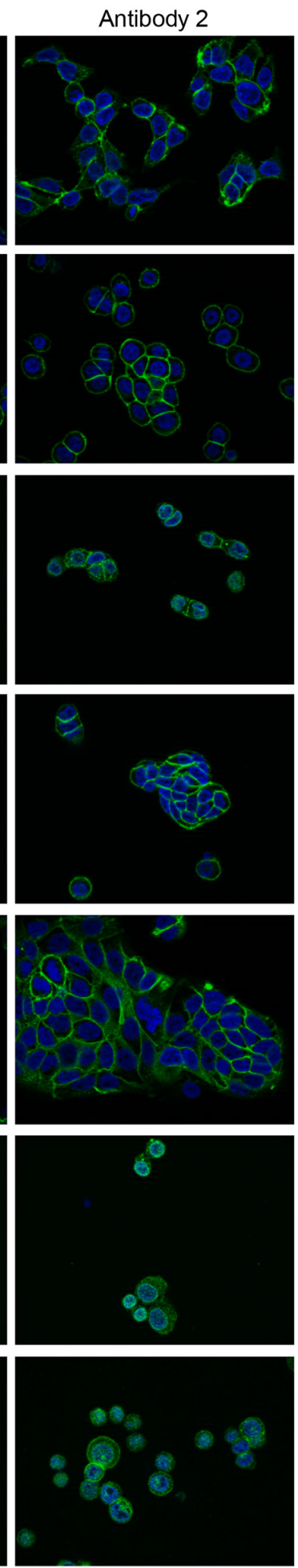

B
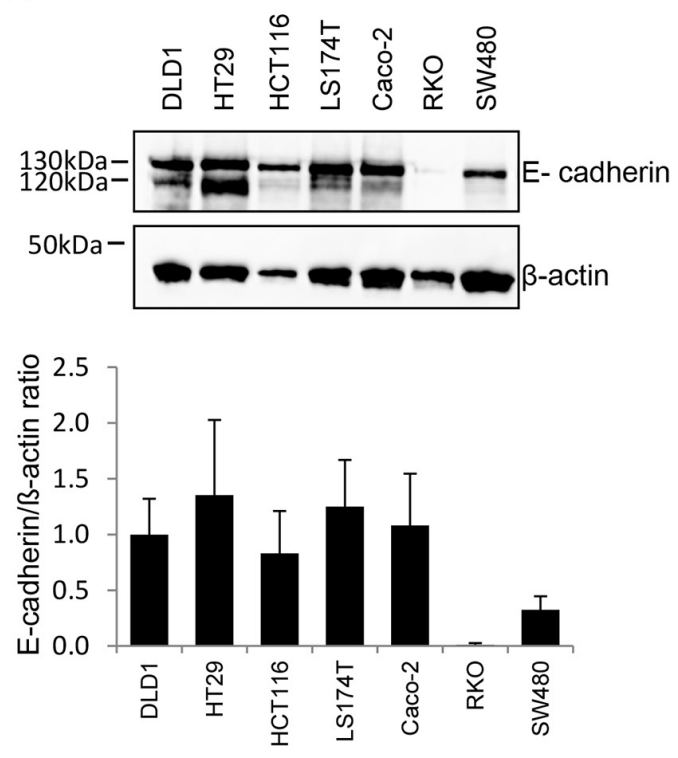

C
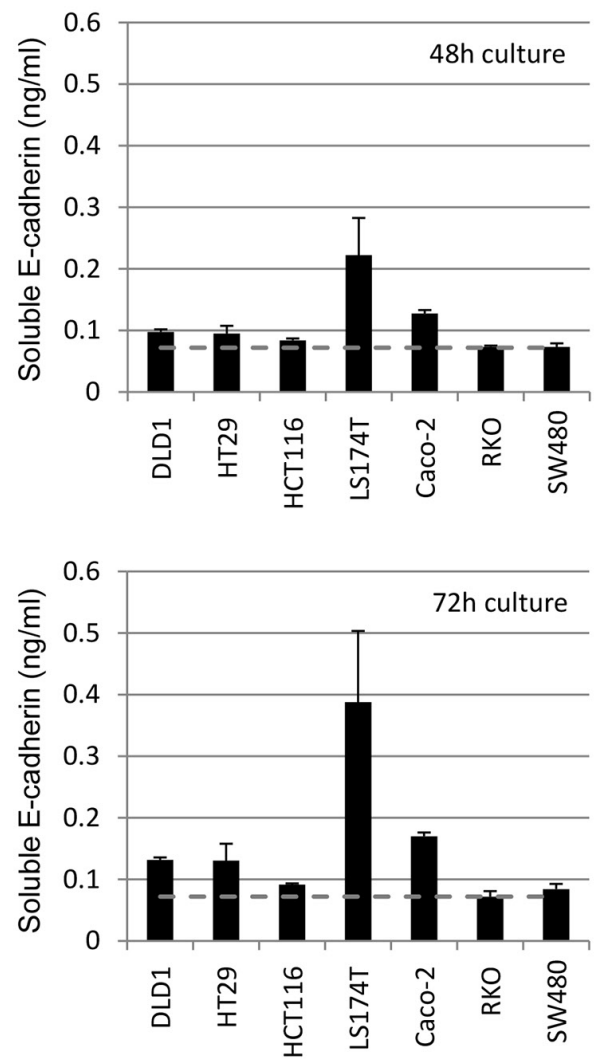

Figure 3: Distinct E-cadherin expression in Cetuximab responding, intermediate-responding and non-responding CRC cell lines. A. CRC cells were stained for E-cadherin (green) and DAPI for visualization of the nucleus (blue). Stainings were performed by two antibodies, with antibody $1=$ clone NCH-38 (DakoCytomation/Agilent), detecting the $120 \mathrm{kDa}$ mature and a $82 \mathrm{kDa}$ soluble E-cadherin, and antibody 2= clone 24E10 (Cell Signaling Technology) raised against P790 of E-cadherin. The representative stainings show a 40x magnification. B. Top:Representative immunoblot for E-cadherin and $\beta$-actin. Note that western blot analysis detects a double band for E-cadherin in DLD1, HT29, LS174T and Caco-2 cells, which correlates to mature (120kDa) and immature (130kDa) E-cadherin. Bottom: Quantification of E-cadherin protein levels. Protein expression normalized to $\beta$-actin. C. Quantification of soluble E-cadherin measured in three independent experiments at $48 \mathrm{~h}$ (top) and $72 \mathrm{~h}$ (bottom) by ELISA. Note that soluble E-cadherin levels were increased upon 72h of cultivation and are highest in LS174T followed by Caco-2, DLD1 and HT29 cells. 
was impaired by 2- to 5-fold as compared to DLD1 cells treated by Cetuximab alone (Figure 4B). DLD1 cells treated with E-cadherin-siRNA alone did not show any significant cell cytotoxicity.

These data point towards a potential important role of E-cadherin in response to Cetuximab in CRC cell lines, since strong or weak membranous expression is associated with responding or non-responding CRC cell lines and since down-regulation of E-cadherin in responding DLD1 cells abrogates response to Cetuximab.

\section{The cohort of colorectal cancer patients receiving EGFR-targeted therapy}

To translate the in vitro findings into a clinicopathological situation, a cohort of 25 CRC patients was next investigated (Table 2). This included tissue specimen based analyses of primary tumors in 24/25 (96\%) and a recurrent tumor in 1/25 (4\%) of CRC cases as well as further case-matched analysis of recurrent tumors $(n=2$, derived from 2/25 CRC cases) and distant liver or lung

A

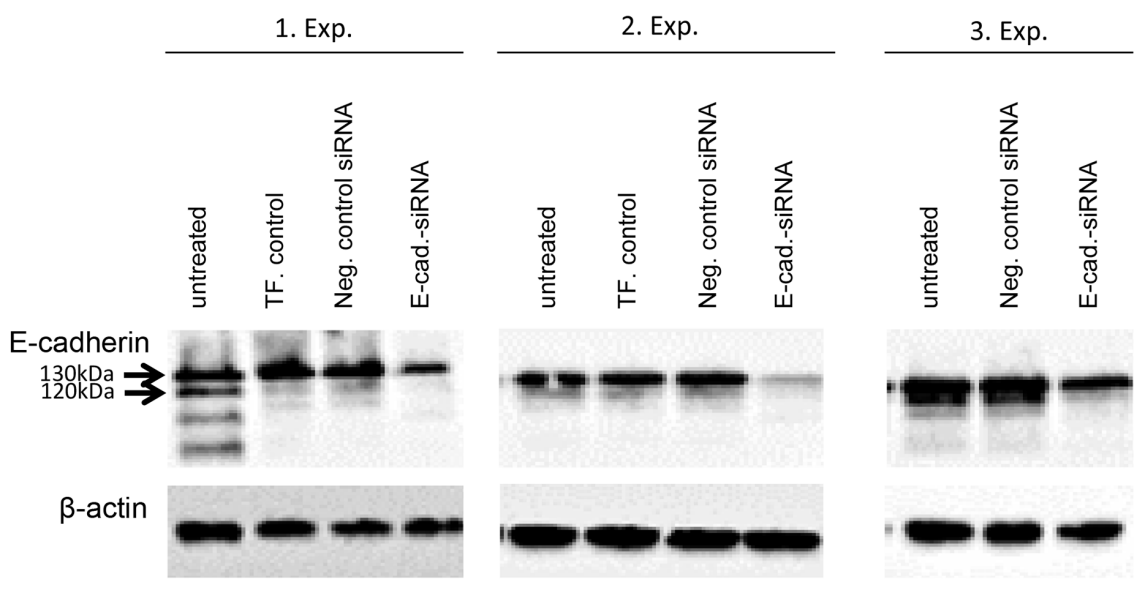

B

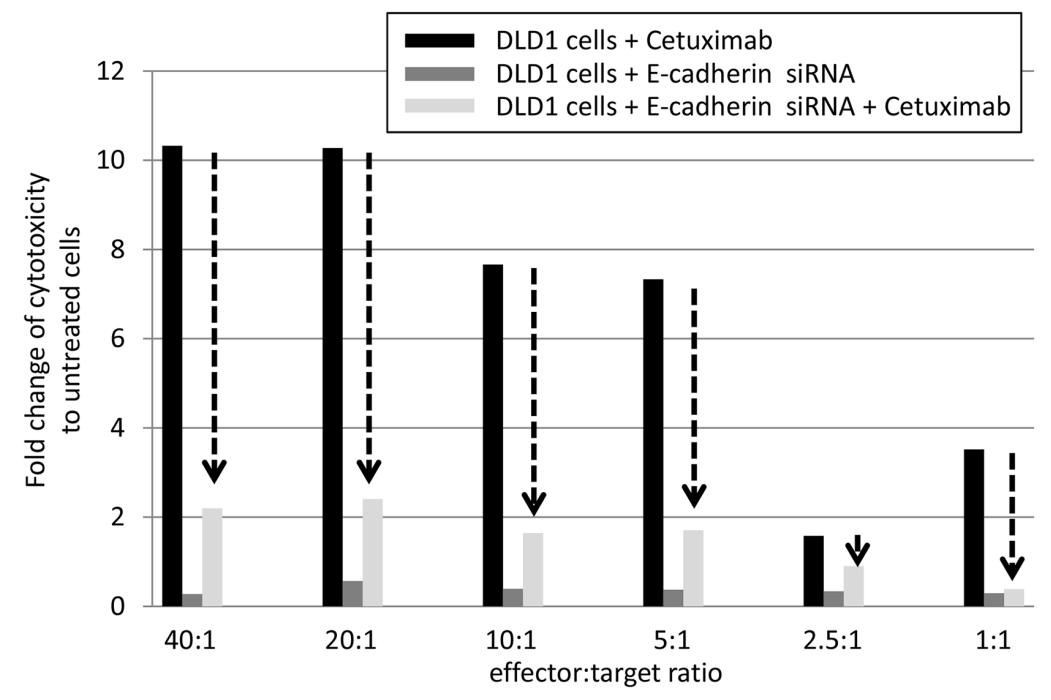

Figure 4: Down-regulation of E-cadherin abrogates response to Cetuximab in DLD1 cells. A. Western blots show three independent experiments of E-cadherin-specific siRNA treatment with associated controls (untreated; TF=transfection control; Neg.Control siRNA= unspecific siRNA). Note the down-regulation of E-cadherin in its immature form (130kDa) and complete loss of its mature form $(120 \mathrm{kDa})$. B. Antibody dependent cellular cytotoxicity (ADCC) measured after co-cultivation of increasing numbers of effector cells (peripheral blood mononuclear cells, PBMCs) with control-siRNA or E-cadherinsiRNA trated DLD1 cells for $4 \mathrm{~h}$ in the absence or presence of $10 \mu \mathrm{g} / \mathrm{ml}$ Cetuximab. Data is presented as fold change of cell cytotoxicity relative to untreated (no Cetuximab, no siRNA) DLD1 cells (each set to 1, bars not shown). Note the loss of Cetuximab responses of DLD1 cells upon down-regulation of E-cadherin by siRNA (arrows). 
metastases ( $n=20$, derived from $12 / 25$ CRC cases). All CRC patients had received EGFR-targeted therapy $(n=13$ Cetuximab; $n=7$ Panitumumab; $n=5$ Cetuximab and Panitumumab). This was combined with chemotherapy in $22 / 25(88 \%)$ of cases. In three cases $(\# 5,15,19)$ EGFR-targeted therapy was given prior to resection of the primary tumor $(\# 5)$, recurrent tumor (\#19) or liver metastasis (\#15). According to the guidelines for initially only KRAS exon 2 and in recent years entire RAS [32] testing, all cases were wildtype for all $25 \mathrm{CRC}$ cases at the time of clinical presentation. Diagnostic reports (external: 2/25; internal: 23/25) of KRAS exon 2 or RAS status were based on dideoxy sequencing in 24/25 CRC cases and on next generation sequencing in $1 / 25 \mathrm{CRC}$ cases. For further molecular classification, microsatellite instability (MSI) and $\mathrm{CpG}$ island methylator phenotype (CIMP, Supplementary Figure 2) status was defined for the $25 \mathrm{CRC}$ cases. This revealed 1/25 (4\%) MSI-positive and 2/25 (8\%) CIMP-positive CRC cases, with 1/25 (4\%) being MSI- and CIMP-positive. All clinico-pathological (including clinical response criteria such as complete or partial response, stable or progressive disease, survival) and molecular (MSI, CIMP) data are given in Table 2.

\section{RAS mutation profiling by targeted next generation sequencing}

To obtain a comprehensive and full picture of the RAS status of CRC cases treated by EGFR-targeted therapy at times when only KRAS exon 2 testing was required, we performed targeted next generation sequencing (tNGS), including all 24 primary tumors, 3 recurrent tumors and 20 distant liver or lung metastases.

The tNGS data underlines the necessity for comprehensive RAS testing in CRCs. In total, 32 KRAS, 11 NRAS and 5 HRAS sequence variants were detected in the 47 tissue specimens of the CRC cohort. Thereby, 8/25 CRC cases presented with RAS "hotspot" mutations, which were maintained for case-matched tissue specimens upon disease progression. These RAS mutations were either in KRAS exon 2 previously undetected by dideoxy sequencing (case \#2), in NRAS exon 2 (case \#1), in KRAS/NRAS exon 3 (cases \#7, \#14, \#16, \#21, \#23), in HRAS exon 2 (case \#22), or were other KRAS/NRAS sequence variants documented in COSMIC without known therapeutic relevance so far (case \#2) (Table 3).

Hence, broader RAS testing and more sensitive technologies, such as tNGS, improve detection of possible $\mathrm{K} / \mathrm{N} / \mathrm{HRAS}$ resistance mutations for EGFR-targeted therapy.

\section{Broad mutation profiling reveals a high frequency of mutations in receptor tyrosine kinases and genes of the RAS/MAPK and PI3K/ AKT pathways}

In addition to RAS mutations, tNGS sequencing revealed novel insights into the mutation profile of the 47 tissue specimens from CRC patients treated by EGFRtargeted therapy.

First, the mutational load showed inter- and intrapatient variability (Figure 5A): The number of mutations ranged from $\mathrm{n}=2$ to $\mathrm{n}=97$ mutations in 24 primary tumors and 3 recurrent tumors at time of initial clinical presentation, and from $n=1$ to $n=86$ mutations in 20 liver or lung metastases. In case-matched metastases, the mutational load was either maintained $(1 / 12 ; 8.3 \%$ cases $)$, increased $(6 / 12 ; 50 \%$ cases $)$ or decreased $(5 / 12 ; 41.7 \%$ cases $)$.

Second, the most frequently mutated genes in all 47 analyzed tissue specimens were TP53 and APC, followed by mutations in ATM, SMAD4, KDR, ErBB4, FBXW7 and others, including KRAS, NRAS and HRAS (Figure $5 B)$. Focusing on genes coding for receptor tyrosine kinases (including EGFR, ERBB2, ERBB4, FGFR2, FGFR3, PDGFRA, KDR/"VEGFR") and associated genes of the RAS/MAPK and PI3K/AKT pathways the evaluation revealed mutations in EGFR in $25.5 \%$, KRAS in $38.3 \%$, BRAF in $21.3 \%$, PI3KCA in $27.7 \%$, AKT in $10.6 \%$ and PTEN in $21.3 . \%$ of cases (Figure 6A). Of these, all detected mutations in EGFR affect tyrosine kinase domains or ligand binding domains and were found widely distributed over EGFR exons 3,7,15,18,19,21 (Supplementary Table 1A). Since the recently described EGFR exon 12 p.G465 and p.S492 Cetuximab resistance mutations, described as occurring during EGFR-treatment [33], were not covered by tNGS, these were further determined by dideoxy sequencing. Neither EGFR exon 12 p.G465 nor p.S492 were mutated in the 25 CRC cases. However, a known single-nucleotide polymorphism was detected in EGFR intron 12/13 (dbSNP: rs1558544) in 7/25 CRC cases.

Finally, mutation profiles in EGFR signaling pathways were analyzed in a case-specific manner (Figure 6B; Supplementary Table 2): Within primary/ recurrent tumors, exclusive receptor tyrosine kinase or RAS/MAPK mutations were observed in 6/25 (24\%) or $4 / 25(16 \%)$ of cases, respectively. In contrast, exclusive PI3K/AKT mutations were not detectable in primary/recurrent tumors, whereby mostly PIK3CA exon 9 and 20 mutations (Supplementary Figure 3, Supplementary Table 3) were seen in combination with other alterations. In 9/25 (36\%) primary/recurrent tumors, mutations of receptor tyrosine kinases, RAS/ MAPK and PI3K/AKT were present. In this setting, the receptor tyrosine kinases, RAS/MAPK and PI3K/ AKT mutation profiles detected in the primary/recurrent tumors diverged upon metastasis in 9/12 (75\%) of cases. Case-matched liver or lung metastases carried only receptor tyrosine kinase or RAS/MAPK mutations in $4 / 12(16 \%)$ of cases and presented with mutations in receptor tyrosine kinases, RAS/MAPK and PIK3CA/ AKT in 4/12 (16\%) of cases.

These data show that complex mutation profiles may influence the response to EGFR-targeted therapy in CRC and possibly also the associated combination therapies. 
Table 2: Detailed patients' characteristics

\begin{tabular}{|c|c|c|c|c|c|c|c|c|c|c|c|c|c|}
\hline ID & $\operatorname{sex}$ & age & TU/M & $\begin{array}{c}\text { tumor } \\
\text { site }\end{array}$ & $\mathbf{p T}$ & $\mathbf{p N}$ & G & CIMP & $\begin{array}{l}\text { MSI } \\
\text { MSS }\end{array}$ & $\begin{array}{c}\text { EGFR-targeted } \\
\text { Tx } \\
\end{array}$ & concurrent $T x$ & $\begin{array}{c}\text { Response } \\
\text { rate }\end{array}$ & $\begin{array}{c}\begin{array}{c}\text { OS } \\
\text { (months) }\end{array} \\
\end{array}$ \\
\hline 1 & $\mathrm{f}$ & 63 & $\begin{array}{c}\text { PT } \\
\mathrm{M}(\mathrm{HEP}) \\
\mathrm{M}(\mathrm{HEP})\end{array}$ & rectum & 3 & 0 & 2 & negative & MSS & $\begin{array}{c}\text { Cetuximab } \\
\text { Panitumumab }\end{array}$ & $\begin{array}{c}\text { Bevacizumab } \\
\text { Capecitabine } \\
\text { Xelox }\end{array}$ & $\mathrm{SD} / \mathrm{PD}$ & 26 \\
\hline 2 & $\mathrm{~m}$ & 69 & $\begin{array}{l}\text { PT } \\
\text { ReT }\end{array}$ & rectum & 2 & 0 & 2 & negative & MSS & Panitumumab & & PD & 1 \\
\hline 3 & $\mathrm{~m}$ & 58 & $\begin{array}{c}\text { PT } \\
\mathrm{M}(\mathrm{HEP})\end{array}$ & rectum & 3 & 2 & 2 & negative & MSS & $\begin{array}{c}\text { Cetuximab } \\
\text { Panitumumab }\end{array}$ & $\begin{array}{c}\text { Bevacizumab } \\
\text { FOLFOX } \\
\text { FOLFIRI }\end{array}$ & $\mathrm{PR} / \mathrm{CR} / \mathrm{PD}$ & 89 \\
\hline 4 & $\mathrm{~m}$ & 70 & PT & colon & 3 & 0 & 2 & negative & MSS & Cetuximab & Irinotecan & $\mathrm{PR} / \mathrm{PD}$ & 10 \\
\hline 5 & $\mathrm{f}$ & 60 & PT & colon & 4 & 0 & 3 & negative & MSS & Cetuximab & FOLFOXIRI & $\mathrm{PR} / \mathrm{CR}$ & \\
\hline 6 & $\mathrm{~m}$ & 69 & PT & colon & 3 & 1 & 2 & negative & MSS & $\begin{array}{c}\text { Cetuximab } \\
\text { Panitumumab }\end{array}$ & Irinotecan & $\mathrm{PR} / \mathrm{PD}$ & 13 \\
\hline 7 & $\mathrm{f}$ & 66 & PT & rectum & 3 & 0 & & negative & MSS & Cetuximab & FOLFIRI & $\mathrm{SD}$ & \\
\hline 8 & $\mathrm{f}$ & 61 & $\begin{array}{c}\text { PT } \\
\mathrm{M}(\mathrm{HEP})\end{array}$ & colon & 4 & 1 & 2 & negative & MSS & $\begin{array}{c}\text { Cetuximab } \\
\text { Panitumumab }\end{array}$ & $\begin{array}{l}\text { Irinotecan } \\
\text { Capiri }\end{array}$ & $\mathrm{SD} / \mathrm{PD}$ & 38 \\
\hline 9 & $\mathrm{~m}$ & 37 & $\begin{array}{c}\mathrm{PT} \\
\mathrm{M}(\mathrm{PUL}) \\
\mathrm{M}(\mathrm{PUL}) \\
\mathrm{M}(\mathrm{HEP}) \\
\mathrm{M}(\mathrm{PUL})\end{array}$ & rectum & 3 & 2 & 2 & negative & MSS & Cetuximab & Irinotecan & $\mathrm{SD} / \mathrm{PD}$ & 15 \\
\hline 10 & $\mathrm{~m}$ & 75 & PT & rectum & 3 & 0 & 2 & negative & MSS & Cetuximab & Irinotecan & $\mathrm{PD}$ & 8 \\
\hline 11 & $f$ & 77 & PT & colon & 4 & 2 & 2 & negative & MSS & Panitumumab & FOLFIRI & PD & 0.5 \\
\hline 12 & $\mathrm{~m}$ & 71 & $\begin{array}{c}\text { PT } \\
\mathrm{M}(\mathrm{HEP})\end{array}$ & colon & 3 & 2 & 2 & negative & MSS & Panitumumab & FOLFOX & PR & \\
\hline 13 & $\mathrm{~m}$ & 64 & $\begin{array}{c}\text { PT } \\
\mathrm{M}(\mathrm{HEP})\end{array}$ & colon & 3 & 1 & 2 & negative & MSS & Cetuximab & $\begin{array}{l}\text { Bevacizumab } \\
\text { Irinotecan } \\
\text { FOLFOX } \\
\text { FOLFIRI }\end{array}$ & $\mathrm{SD} / \mathrm{PD}$ & 10 \\
\hline 14 & $\mathrm{f}$ & 65 & $\begin{array}{c}\text { PT } \\
\mathrm{M}(\mathrm{HEP})\end{array}$ & colon & 4 & 2 & 2 & negative & MSS & Cetuximab & Irinotecan & PD & 6 \\
\hline 15 & $\mathrm{f}$ & 63 & $\begin{array}{c}\text { PT } \\
\text { ReT } \\
\mathrm{M}(\mathrm{HEP})\end{array}$ & $\begin{array}{c}\text { rectum/ } \\
\text { sigma }\end{array}$ & 2 & 1 & 2 & negative & MSS & Cetuximab & FOLFIRI & $\mathrm{CR} / \mathrm{PR}$ & 28 \\
\hline 16 & $\mathrm{f}$ & 70 & $\begin{array}{c}\text { PT } \\
\text { M(HEP }) \\
\text { M(HEP })\end{array}$ & colon & 4 & 1 & 3 & negative & MSS & Panitumumab & & PD & 7 \\
\hline 17 & $\mathrm{~m}$ & 46 & $\begin{array}{c}\text { PT } \\
\mathrm{M}(\mathrm{HEP})\end{array}$ & colon & 3 & 2 & 2 & na & MSS & Cetuximab & Irinotecan & $\mathrm{PR} / \mathrm{PD}$ & 11 \\
\hline 18 & $\mathrm{~m}$ & 74 & PT & colon & 3 & 2 & 3 & $\begin{array}{c}\text { positive } \\
(4 / 5)\end{array}$ & MSI & Cetuximab & FOLFIRI & $\mathrm{PD}$ & 5 \\
\hline 19 & $\mathrm{~m}$ & 73 & $\operatorname{ReT}$ & colon & 4 & 0 & 2 & $\begin{array}{c}\text { positive } \\
(3 / 5)\end{array}$ & MSS & Panitumumab & & & \\
\hline 20 & $\mathrm{~m}$ & 61 & $\begin{array}{c}\text { PT } \\
\text { M(HEP) } \\
\text { M(HEP })\end{array}$ & rectum & 3 & 1 & 2 & negative & MSS & Cetuximab & FOLFIRI & & \\
\hline 21 & $\mathrm{f}$ & 59 & PT & colon & 4 & 2 & 3 & negative & MSS & Cetuximab & Irinotecan & $\mathrm{PD}$ & 3 \\
\hline 22 & $\mathrm{~m}$ & 63 & PT & colon & 4 & 2 & 2 & negative & MSS & Panitumumab & FOLFOX & $\mathrm{PR} / \mathrm{PD}$ & \\
\hline 23 & $f$ & 68 & PT & rectum & 3 & 2 & 2 & negative & MSS & Cetuximab & Irinotecan & $\mathrm{PD}$ & 20 \\
\hline 24 & $\mathrm{~m}$ & 41 & PT & colon & 3 & 2 & 2 & negative & MSS & Panitumumab & FOLFOX & & \\
\hline 25 & $\mathrm{~m}$ & 59 & $\begin{array}{c}\text { PT } \\
\text { M(HEP) } \\
\text { M(PUL) } \\
\text { M(PUL) }\end{array}$ & rectum & 3 & 2 & 2 & negative & MSS & $\begin{array}{c}\text { Cetuximab } \\
\text { Panitumumab }\end{array}$ & Bevacizumab & PR & \\
\hline
\end{tabular}

The table summarizes the major clinico-pathological parameters and molecular (MSI, CIMP) data of the investigated 25 cases. Capiri=Capecitabine, Irinotecan; Xelox=Capecitabine, Oxaliplatin; FOLFOX=Leucovorin, 5-FU, Oxaliplatin; FOLFIRI=Leucovorin, 5-FU, Irinotecan;

FOLFOXIRI=Leucovorin, 5-FU, Oxaliplatin, Irinotecan. Clinical response data is given as SD=stable disease (responders), PD=progressive disease (nonresponder), $\mathrm{CR}=$ complete response, $\mathrm{PR}=$ partial response as well as overall survival (length of time from start anti-EGFR treatment to death of patient). 
Table 3: RAS mutations detected by next generation sequencing

\begin{tabular}{|c|c|c|c|c|c|c|}
\hline Case ID & & $\begin{array}{c}\begin{array}{c}\text { Tissue } \\
\text { specimen }\end{array} \\
\end{array}$ & Gene & Exon & Mutation & $\begin{array}{c}\% \text { allele } \\
\text { frequency }\end{array}$ \\
\hline \multirow{3}{*}{1} & \multirow{3}{*}{2005} & PT & NRAS & 2 & p.Gly13Arg & 55.63 \\
\hline & & M(HEP) & NRAS & 2 & p.Gly13Arg & 46.54 \\
\hline & & M(HEP) & NRAS & 2 & p.Gly13Arg & 84.54 \\
\hline \multirow{5}{*}{2} & \multirow{2}{*}{2012} & \multirow{2}{*}{ PT } & KRAS & 2 & p.Gly12Asp & 61.39 \\
\hline & & & NRAS & 2 & p.Gly10Glu & 10.3 \\
\hline & \multirow{3}{*}{2013} & \multirow{3}{*}{$\operatorname{ReT}$} & KRAS & 2 & p.Gly12Asp & 24.29 \\
\hline & & & KRAS & 2 & p.Ala18Thr & 16.57 \\
\hline & & & KRAS & 3 & p.Glu63Lys & 30.48 \\
\hline 7 & 2012 & PT & KRAS & 3 & p.Gln61Arg & 39.72 \\
\hline \multirow{2}{*}{14} & 2012 & PT & KRAS & 3 & p.Gln61His & 97.95 \\
\hline & 2012 & M(HEP) & KRAS & 3 & p.Gln61His & 34.49 \\
\hline \multirow{3}{*}{16} & \multirow{3}{*}{2010} & PT & KRAS & 3 & p.Thr58Ile & 36.69 \\
\hline & & M(HEP) & KRAS & 3 & p.Thr58Ile & 65.31 \\
\hline & & M(HEP) & KRAS & 3 & p.Thr58Ile & 19.9 \\
\hline 21 & 2012 & PT & KRAS & 3 & p.Gln61Lys & 59.72 \\
\hline 22 & 2014 & PT & HRAS & 2 & p.Gly12Asp & 14.8 \\
\hline 23 & 2008 & PT & KRAS & 3 & p.Gln61Leu & 23.23 \\
\hline
\end{tabular}

Note that at time of treatment decision making and predictive testing, only KRAS exon 2 testing was performed, i.e. not including KRAS codons 58 (case \#16) and 61 (cases \#7, \#14, \#21, \#23) or NRAS exon 2 (case \#1). For case \#2, dideoxy sequencing at that time did not detect the KRAS exon 2 mutation. HRAS testing (case \#22) is still not included in diagnostic RAS testing guidelines.

\section{EGFR expression and EGFR promoter methylation in CRC}

To test whether in vitro observed EGFR expression and its regulation by DNA methylation is also seen in situ, EGFR promoter methylation, mRNA and protein expression were analyzed in 24 primary tumors, 3 recurrent tumors and 17 distant liver or lung metastases. (Figure 7, Table 4). EGFR promoter methylation analysis was omitted from the 3 metastatic lesions of case \#25, which showed high EGFR mRNA and protein expression due to an EGFR gene amplification.

As assessed by pyrosequencing of $3 \mathrm{CpG}$ sites, EGFR promoter methylation ranged from 3\% to $64.3 \%$ in primary tumors and from $1.3 \%$ to $56.3 \%$ in metastases (Table 4).

The relative EGFR mRNA expression was generally low upon comparison to a universal reference RNA (fold change primary/recurrent tumors: 0.008 to 8.039 ; fold change liver or lung metastases: 0 to 4.708$)$. One case (\#25, gene amplification) showed a 78-fold increase of EGFR mRNA expression in the primary tumor and an up to 127 -fold increase in the metastasis (Table 4).
Finally, EGFR protein expression was positive (score $>/=1)$ in $3 / 25(12 \%)$ cases $(\# 9, \# 16, \# 25)$. Case \#9 only showed an EGFR expression of score 1 in one lung metastasis; case \#16 only showed an EGFR expression of score 1 in the primary tumor; case \#25 showed an EGFR expression of score 3 for the primary tumor and one lung metastasis (Figure 7). Further to this, EGFR expression was heterogeneous resulting in a score of 0 , but showing focal EGFR membranous positive tumor cells even within the same tumor glands (Figure 7, cases \#8, \#9).

Hence, indeed $\mathrm{CRC}$ rarely express high levels of membranous EGFR protein, which are not directly regulated by EGFR promoter methylation and mRNA expression (Supplementary Figure 4).

\section{E-cadherin protein expression correlates to response to EGFR-targeted therapy in CRC patients}

To investigate whether or not other cellular mechanisms involved in CRC metastasis may predict response to EGFR-targeted therapy [24], we stained 24 primary tumors, 3 recurrent tumors and associated 18 
metastases for E-cadherin protein expression (Figure 8, Table 5). As for the in vitro experiments above, this was performed with two commercially available antibodies: The first antibody (clone NCH-38, DakoCytomation/ Agilent) recognizes the $120 \mathrm{kD}$ mature form and a $82 \mathrm{kD}$ (soluble) fragment of E-cadherin. The second antibody (clone 24E10, Cell Signaling Technology) recognizes P780 of E-cadherin and stains cytoplasmic E-cadherin.

Immunohistochemical analyses revealed that E-cadherin was expressed in all 25 CRC cases, with E-cadherin expression in normal epithelia being high

\section{A}

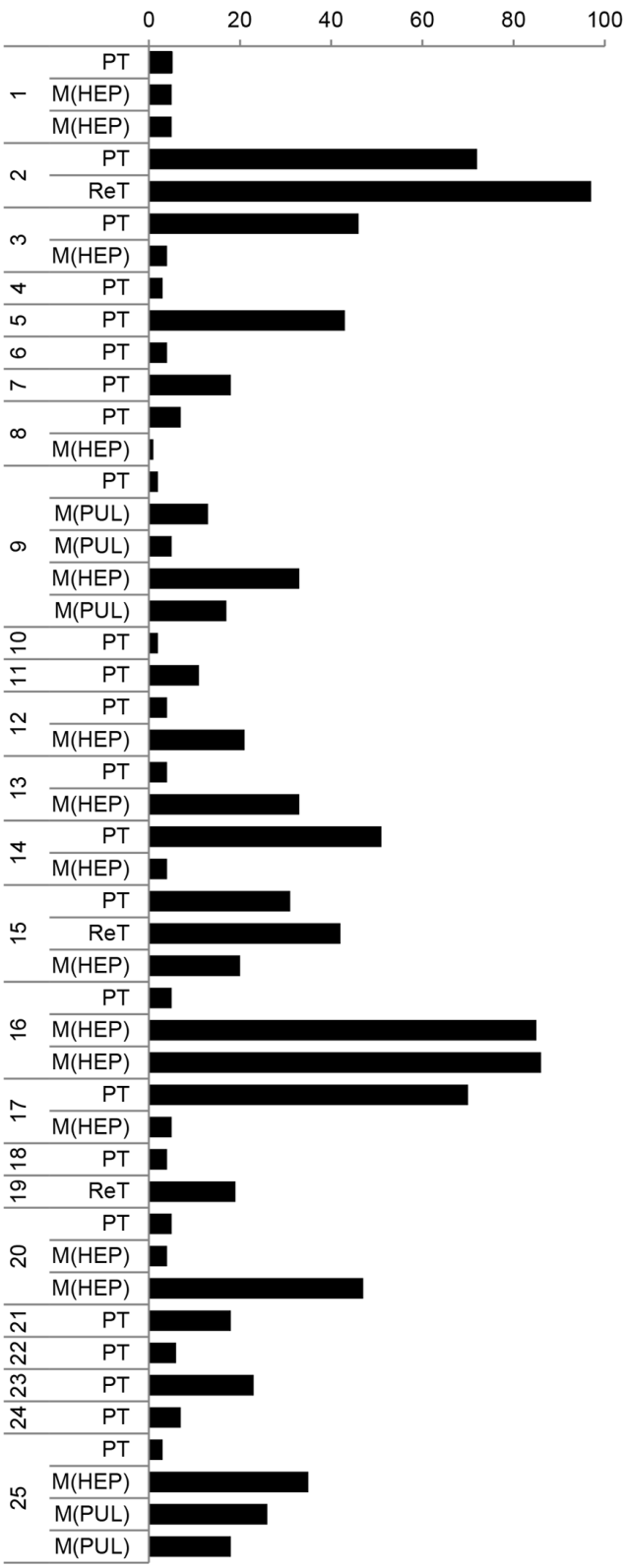

(IRS score 12) in 15/25 cases and low (IRS score range 2 to 8 ) in 10/25 cases. E-cadherin protein expression was mostly maintained in case-matched primary tumors and metastases, except in three cases (\#16, \#17, \#20) with either higher (\#17, \#20) or lower (\#16) IRS scores for E-cadherin expression in metastases. Indeed, in 4/25 cases, primary tumors $(\# 15, \# 20, \# 22)$ and liver (\#15, \#16) metastases showed heterogeneous E-cadherin expression as defined by the number of positive tumor cells (i.e. scored for category " $51-80 \%$ " positivity) (Table 5). There was no case with complete E-cadherin negativity and

B

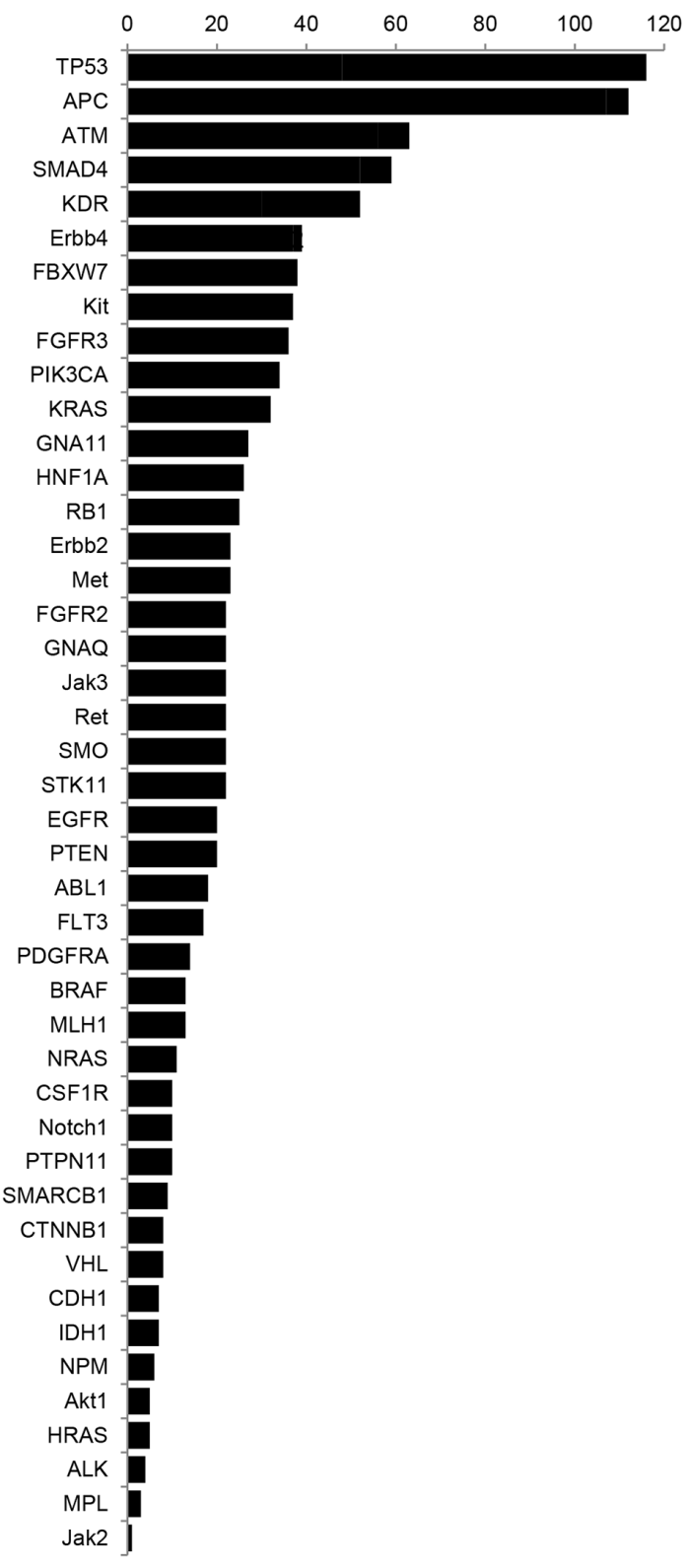

Figure 5: Case- and gene-specific frequency of detected variants is divergent within the CRC cohort. A. Case-specific listing of the number of sequence variants. Missense, stop gained and frameshift mutations are included. B. Case-mixed listing of the mutated genes according to mutation frequency. 
both used antibodies showed similar expression patterns (Figure 8A). Nevertheless, in a single case with low E-cadherin expression (\#11, primary tumor), membranous staining appeared to be more prominent by antibody 2 as compared to antibody 1 (Figure 8A). Since entire tissue specimen sections were used for immunohistochemical staining, artefacts due to non-representative selected tissue areas can be ruled out.

Finally, upon classification of primary tumors of cases with clinical follow-up $(\mathrm{n}=17)$ into "E-cadherin score $<12$ " $(n=8)$ versus "E-cadherin score=12" $(n=9)$, the median overall survival of E-cadherin strong positive cases was better than in those cases with lower E-cadherin expression (Figure 8B).

\section{A matrix for response prediction to EGFR- targeted therapy in CRC}

Of the generated data, RAS status, BRAF, PIK3CA, ATM mutations as well as E-cadherin expression appeared to correlate with responses of CRC cell lines and cases to EGFR-targeted therapy. In order to provide a synopsis of their predictive value, CRC cell lines and cases were defined as responders, intermediate responders and nonresponders followed by integration of the key alterations investigated. The classification was by the ADCC data for cell lines (Figure 1) and by known clinical response parameters of "partial/complete response", "stable/ progressive disease" and survival data for CRC cases (Table 2).

\section{A}
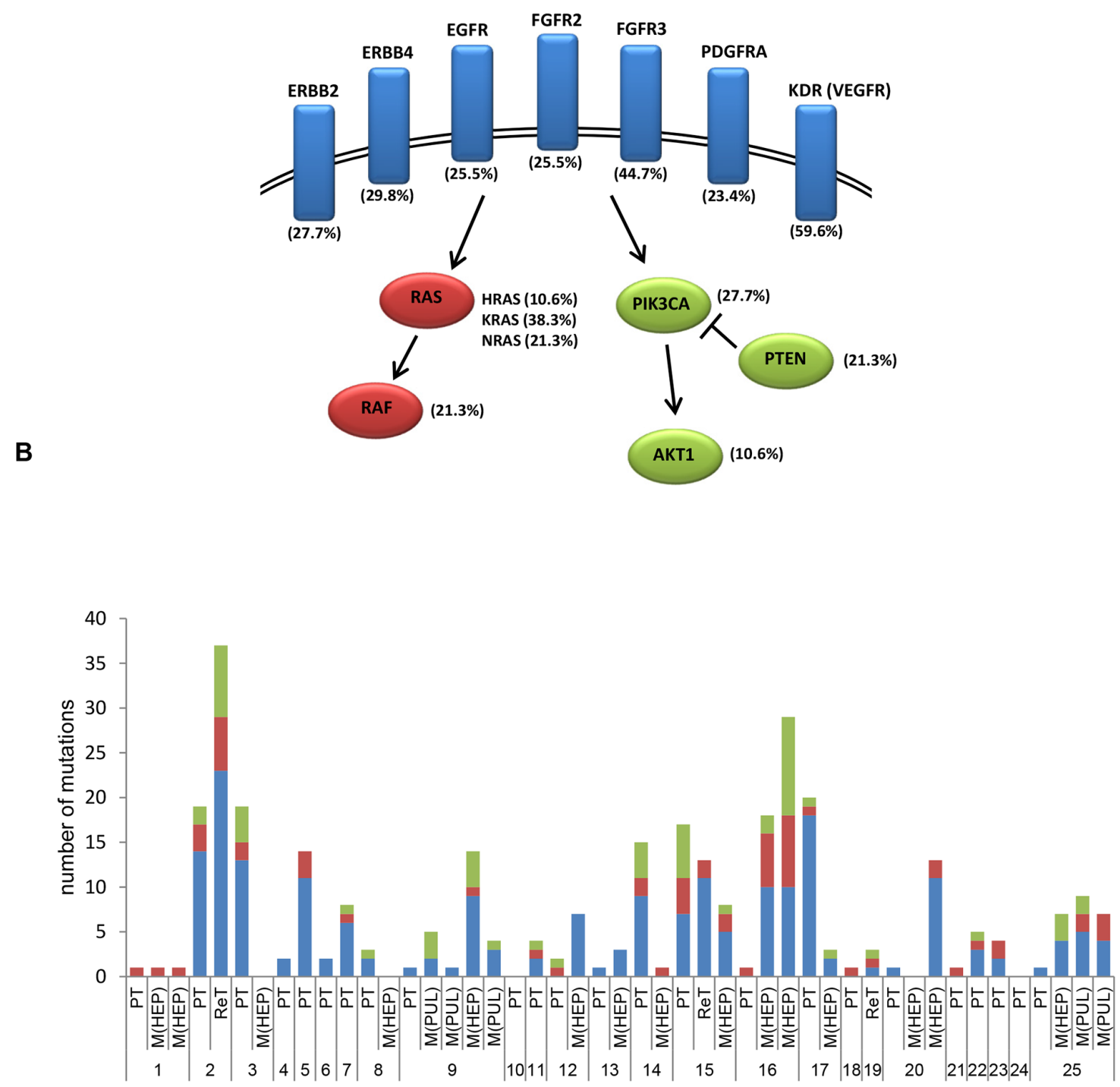

Figure 6: Mutations in receptor tyrosine kinases, RAS/MAPK and PI3K/AKT pathways in EGFR-treated CRC cases. A. Frequency of detected mutations in receptor tyrosine kinases (highlighted in blue) and associated genes of the RAS/MAPK (highlighted in red) and PI3K/AKT (highlighted in green) pathways. B. Case-specific frequency of mutations in receptor tyrosine kinase (blue), RAS/ MAPK (red) and PIK3/AKT (green) pathways. 
As depicted in Table 6 for primary tumors, the MSI and CIMP status as well as EGFR expression are not of predictive value in the present cohort. Similarly, RAS mutations were actually present in responders, intermediate responders and non-responders. The same is true for BRAF and PIK3CA mutations in general. However, when specifying PIK3CA mutations, the responding cell line (DLD1) and CRC patients (\#3, \#8) harbored the same PIK3CA exon 9 mutations, whereas intermediate responders and non-responders carried the same PIK3CA exon 20 mutations (HCT116, LS174T, RKO cell lines, and recurrent tumor, primary tumor or metastases of CRC cases \#2, \#14, \#16). In contrast, ATM mutations and E-cadherin expression appear to stratify responders (ATM wildtype sequences and high E-cadherin expression) from intermediate responders and non-responders (ATM mutations and low E-cadherin expression).
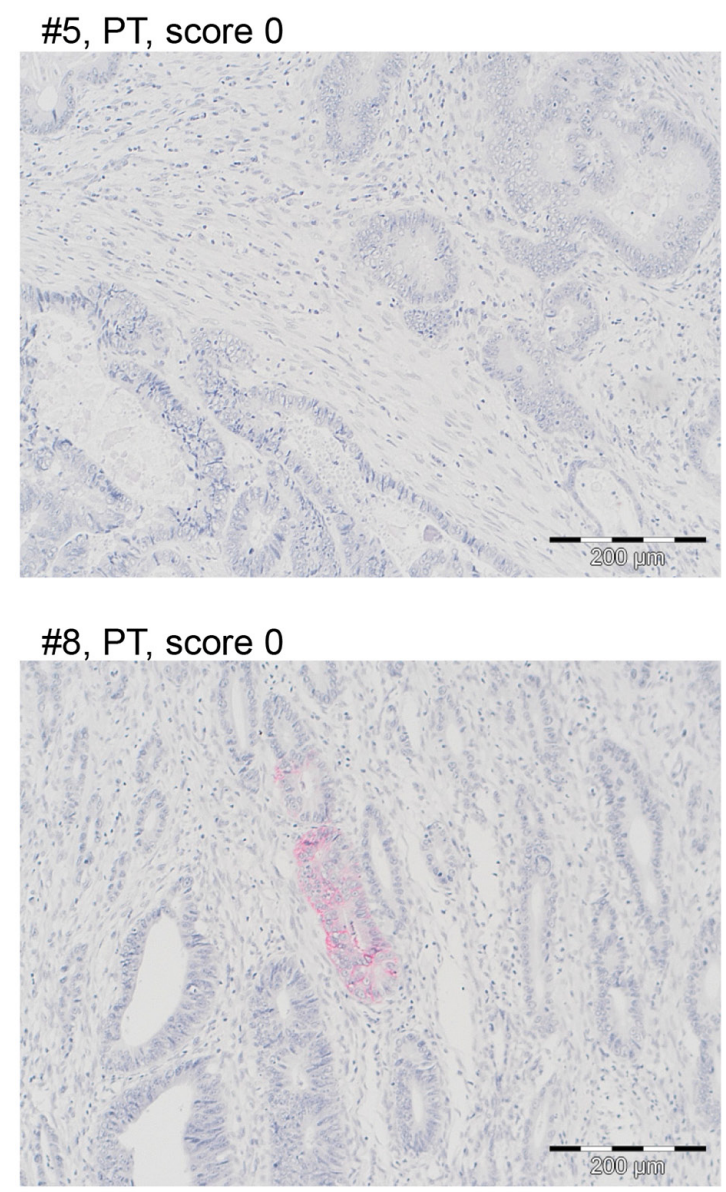

\section{DISCUSSION}

Treatment of metastatic colorectal cancer (CRC) patients may include EGFR-targeted therapy if the tumor does not harbor an activating downstream RAS mutation. The monoclonal anti-EGFR antibody (Cetuximab, Panitumumab) based therapies are hence considered to be effective even without prior detection of EGFR protein expression [34]. Still, even RAS mutated CRCs may be responsive and vice-versa also RAS wildtype CRCs may be resistant to EGFR-targeted therapy. To elucidate potential mechanisms underlying treatment responses to EGFR-targeted therapy, we here comprehensively investigated $7 \mathrm{CRC}$ cell lines and tissue specimens of 25 CRC patients for putative resistance mechanisms residing within the target (i.e. EGFR), mutations of downstream signaling pathways or in bypass receptor tyrosine kinases as well as E-cadherin expression. Indeed, ATM and PIK3CA mutations as well as E-cadherin expression may represent supplementary
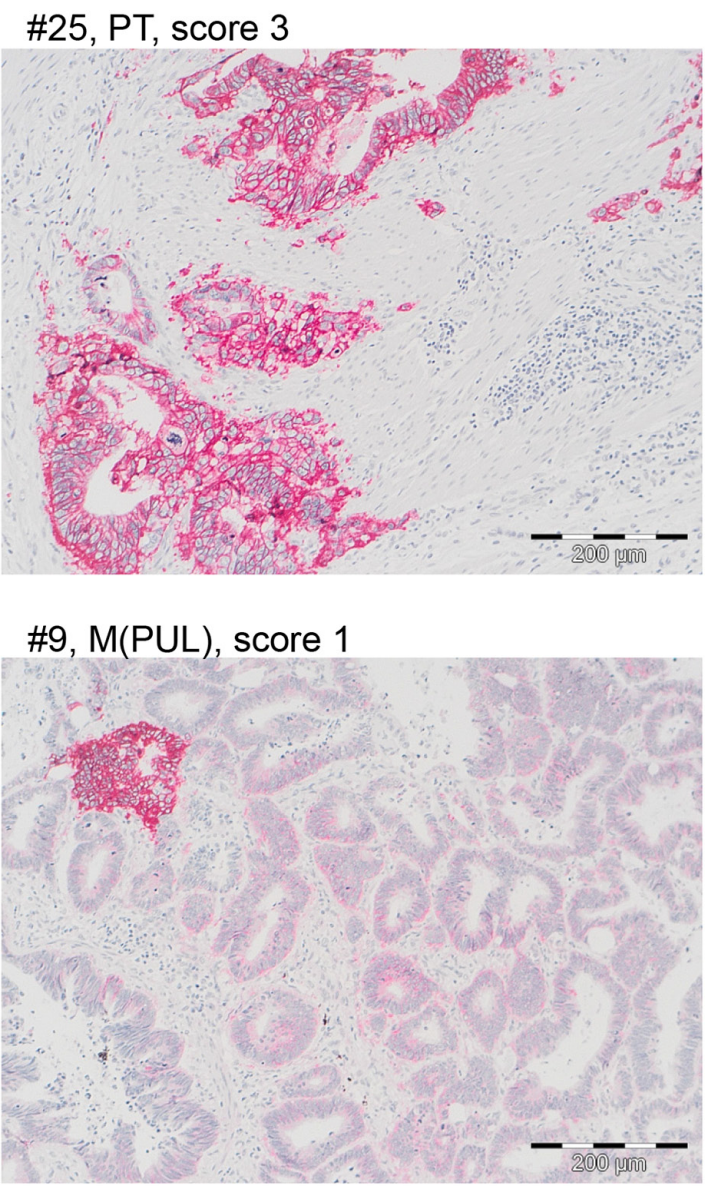

Figure 7: EGFR protein is rarely expressed in CRC tissue specimens. A Representative EGFR stainings of four CRC cases with scores 0 (\#5,\#8), 1 (\#9) and 3 (\#25). Scoring was performed according to Fichter et al. [63]. Bar $=200 \mu \mathrm{m}$. Note that CRC cases \#8 and \#9 showed intratumoral and intraglandular heterogeneity. 
Table 4: Molecular alterations of EGFR at the DNA, RNA and protein levels

\begin{tabular}{|c|c|c|c|c|}
\hline Case ID & Tissue specimen & $\begin{array}{c}\text { EGFR methylation } \\
(\%)\end{array}$ & $\begin{array}{c}\text { EGFR mRNA } \\
\text { expression }\end{array}$ & $\begin{array}{c}\text { EGFR protein } \\
\text { expression }\end{array}$ \\
\hline \multirow{4}{*}{1} & NO & 8.3 & n.a. & 0 \\
\hline & PT & 12.7 & 0.008 & 0 \\
\hline & M(HEP) & 20.0 & 0.000 & 0 \\
\hline & M(HEP) & 11.3 & 0.147 & 0 \\
\hline \multirow{3}{*}{2} & NO & 1.3 & n.a. & 0 \\
\hline & PT & 3.0 & 4.733 & 0 \\
\hline & $\operatorname{ReT}$ & 11.3 & 1.402 & 0 \\
\hline \multirow{3}{*}{3} & NO & 1.7 & n.a. & 0 \\
\hline & PT & 7.7 & 0.108 & 0 \\
\hline & M(HEP) & 6.7 & 1.799 & 0 \\
\hline \multirow{2}{*}{4} & NO & 1.0 & n.a. & 0 \\
\hline & PT & 18.0 & 0.578 & 0 \\
\hline \multirow{2}{*}{5} & NO & 9.3 & n.a. & 0 \\
\hline & PT & 38.7 & 0.314 & $\mathbf{0}$ \\
\hline \multirow{2}{*}{6} & NO & 1.0 & n.a. & 0 \\
\hline & PT & 9.7 & 0.215 & 0 \\
\hline \multirow{3}{*}{7} & NO & 9.3 & n.a. & 0 \\
\hline & PT & 46.0 & 1.096 & 0 \\
\hline & NO & 10.0 & n.a. & 0 \\
\hline \multirow[t]{2}{*}{8} & PT & 12.0 & 2.411 & $\mathbf{0}$ \\
\hline & $\mathrm{M}(\mathrm{HEP})$ & 14.3 & 0.089 & 0 \\
\hline \multirow{6}{*}{9} & NO & 3.3 & n.a. & 0 \\
\hline & $\mathrm{PT}$ & 9.3 & 0.058 & 0 \\
\hline & $\mathrm{M}(\mathrm{PUL})$ & 9.7 & 0.880 & 0 \\
\hline & M(PUL) & 16.7 & 1.722 & 1 \\
\hline & $\mathrm{M}(\mathrm{HEP})$ & 9.7 & 0.864 & 0 \\
\hline & M(PUL) & 6.3 & 1.909 & 0 \\
\hline \multirow{2}{*}{10} & NO & 7.7 & n.a. & 0 \\
\hline & PT & 17.3 & 0.822 & 0 \\
\hline \multirow{3}{*}{11} & NO & 9.0 & n.a. & 0 \\
\hline & $\mathrm{PT}$ & 29.3 & 1.197 & 0 \\
\hline & NO & 5.0 & n.a. & 0 \\
\hline \multirow[t]{3}{*}{12} & PT & 8.3 & 2.596 & 0 \\
\hline & M(HEP) & 20.3 & 4.708 & 0 \\
\hline & NO & 5.0 & n.a. & 0 \\
\hline \multirow[t]{2}{*}{13} & PT & 12.7 & 0.914 & 0 \\
\hline & $\mathrm{M}(\mathrm{HEP})$ & 12.7 & n.d & $\begin{array}{l}\text { n.d } \\
\text { (Contin }\end{array}$ \\
\hline
\end{tabular}




\begin{tabular}{|c|c|c|c|c|}
\hline Case ID & Tissue specimen & $\begin{array}{c}\text { EGFR methylation } \\
(\%)\end{array}$ & $\begin{array}{c}\text { EGFR mRNA } \\
\text { expression }\end{array}$ & $\begin{array}{c}\text { EGFR protein } \\
\text { expression }\end{array}$ \\
\hline \multirow{3}{*}{14} & $\mathrm{NO}$ & 2.0 & n.a. & 0 \\
\hline & PT & 64.3 & 1.883 & 0 \\
\hline & M(HEP) & 13.7 & n.d & n.d \\
\hline \multirow{4}{*}{15} & PT & 19.3 & 0.437 & 0 \\
\hline & NO & 1.7 & n.a. & 0 \\
\hline & reT & 21.3 & 0.520 & 0 \\
\hline & M(HEP) & 33.3 & 0.379 & 0 \\
\hline \multirow{4}{*}{16} & NO & 5.3 & n.a. & 0 \\
\hline & PT & 41.0 & 0.559 & 1 \\
\hline & M(HEP) & 56.3 & 0.884 & 0 \\
\hline & M(HEP) & 7.0 & 1.015 & 0 \\
\hline \multirow{3}{*}{17} & NO & 1.7 & n.a. & 0 \\
\hline & PT & 50.0 & 0.095 & 0 \\
\hline & M(HEP) & 55.7 & 0.271 & 0 \\
\hline \multirow{2}{*}{18} & NO & 19.3 & n.a. & 0 \\
\hline & PT & 15.7 & 0.245 & 0 \\
\hline \multirow{2}{*}{19} & NO & 5.3 & n.a. & 0 \\
\hline & $\operatorname{ReT}$ & 32.0 & 0.691 & 0 \\
\hline \multirow{4}{*}{20} & NO & 2.3 & n.a. & 0 \\
\hline & PT & 18.7 & 0.224 & 0 \\
\hline & M(HEP) & 8.7 & 0.147 & 0 \\
\hline & M(HEP) & 8.7 & 0.047 & 0 \\
\hline \multirow{2}{*}{21} & NO & 3.3 & n.a. & 0 \\
\hline & PT & 27.3 & 8.039 & 0 \\
\hline \multirow{2}{*}{22} & NO & 3.0 & n.a. & 0 \\
\hline & PT & 48.3 & 0.520 & 0 \\
\hline \multirow{2}{*}{23} & NO & 15.3 & n.a. & 0 \\
\hline & PT & 12.3 & 0.079 & 0 \\
\hline \multirow{2}{*}{24} & NO & 0.3 & n.a. & 0 \\
\hline & PT & 20.7 & 0.467 & 0 \\
\hline \multirow{5}{*}{25} & NO & 11.3 & n.a. & 0 \\
\hline & PT & 27.3 & 78.124 & 3 \\
\hline & M(HEP) & n.d. & 127.129 & 1 \\
\hline & $\mathrm{M}(\mathrm{PUL})$ & n.d. & 50.586 & 1 \\
\hline & M(PUL) & n.d. & 87.781 & 3 \\
\hline
\end{tabular}

The table provides the summary of findings of EGFR promoter methylation (mean \% methylation of three CpG sites investigated), EGFR mRNA expression (relative quantification qRT-PCR according to $2^{\wedge}-\Delta \Delta C T$ method [71]) and EGFR protein expression (immunohistochemical scores [63]) analyses. N.a. $=$ not applicable; n.d. $=$ not determined. See text for details. Refer to Figure 7 for representative stainings (cases marked in bold in the table). 
A
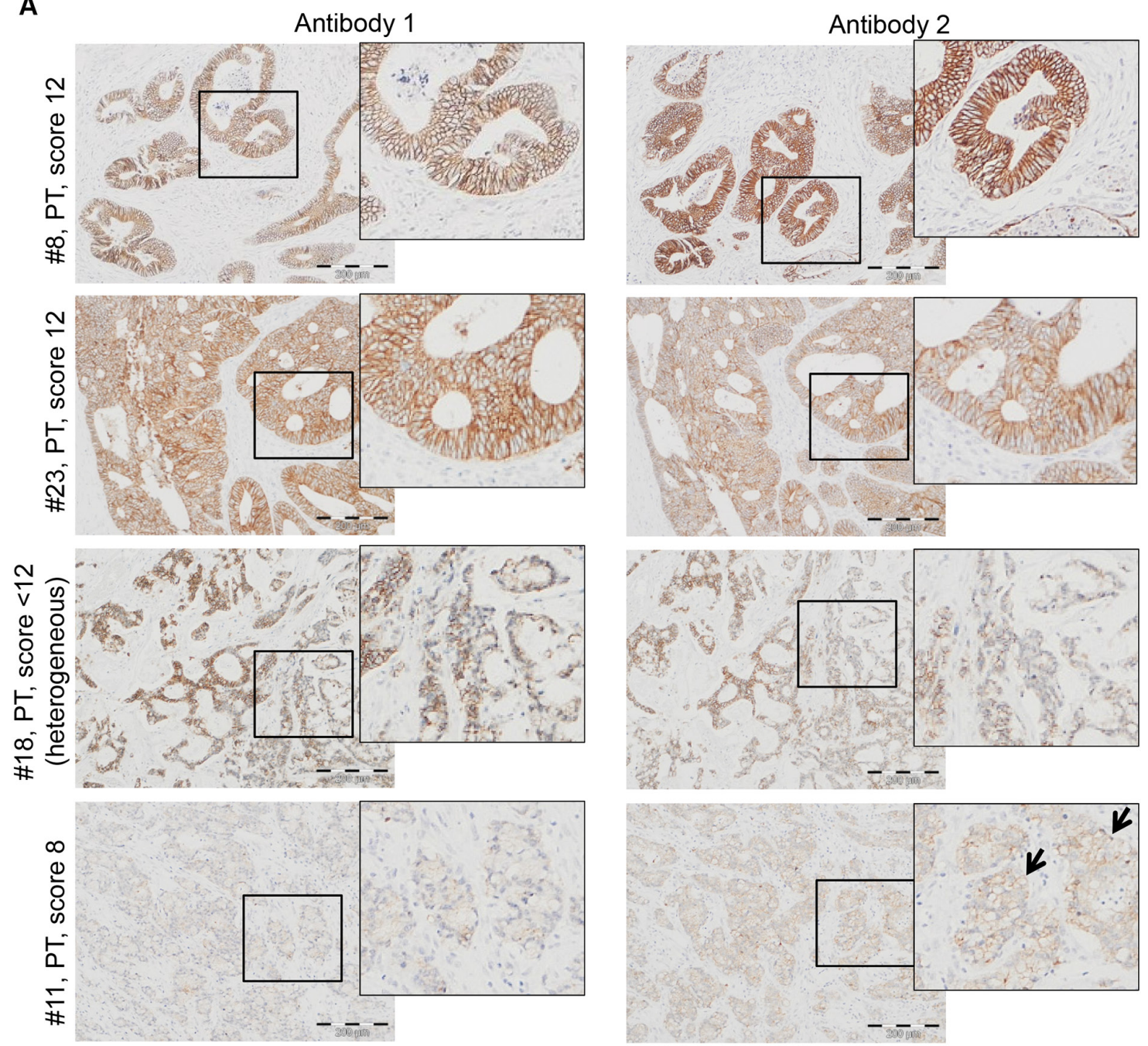

B

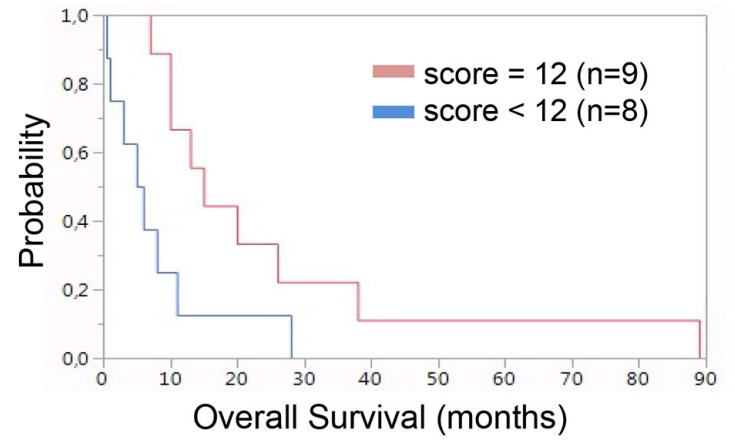

Figure 8: E-cadherin is differentially expressed in CRC and associates with overall survival. A. Representative E-cadherin stainings of two responding (\#8, \#23) and two non-responding (\#18, \#11) CRC cases. Responding cases \#8 and \#12 both exhibit an E-cadherin IRS score of 12. Non-responding cases \#18 and \#11 exhibit an E-cadherin IRS score of $<12$ with heterogeneity and an E-cadherin IRS score of 8, respectively. Note that the two antibodies used for immunohistochemistry (antibody 1: clone NCH-38, DakoCytomation/ Agilent, detects the $120 \mathrm{kDa}$ mature and a $82 \mathrm{kDa}$ soluble E-cadherin; and antibody $2=$ clone $24 \mathrm{E} 10$, Cell Signaling Technology, raised against P780 of E-cadherin) show similar expression patterns, except a slightly more prominent membranous E-cadherin expression for

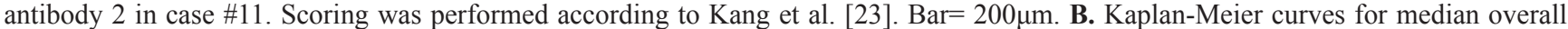
survival (OS) of colorectal cancer cases with IRS score $<12$ (blue line, $n=8$ ) or IRS score $=12$ (red line, $n=9$ ). Median OS rate of patients with IRS score $<12$ was 7.8 months and 25.3 months for patients with IRS score $=12(p=0.026)$. 
Table 5: E-cadherin protein expression in CRC

\begin{tabular}{|c|c|c|c|c|}
\hline \multirow[b]{2}{*}{ Case ID } & \multirow[b]{2}{*}{ Tissue specimen } & \multicolumn{3}{|c|}{ E-cadherin protein expression } \\
\hline & & $\begin{array}{l}\% \text { positive tumor } \\
\text { cells }\end{array}$ & intensity & IRS \\
\hline \multirow{4}{*}{1} & NO & $10-50 \%$ & weak & 2 \\
\hline & PT & $>80 \%$ & strong & 12 \\
\hline & M(HEP) & $>80 \%$ & strong & 12 \\
\hline & $\mathrm{M}(\mathrm{HEP})$ & $>80 \%$ & strong & 12 \\
\hline \multirow{3}{*}{2} & NO & $10-50 \%$ & moderate & 4 \\
\hline & PT & $>80 \%$ & moderate & 8 \\
\hline & $\operatorname{ReT}$ & $>80 \%$ & moderate & 8 \\
\hline \multirow{3}{*}{3} & NO & $>80 \%$ & strong & 12 \\
\hline & PT & $>80 \%$ & strong & 12 \\
\hline & M(HEP) & $>80 \%$ & strong & 12 \\
\hline \multirow{2}{*}{4} & NO & $10-50 \%$ & moderate & 4 \\
\hline & PT & $>80 \%$ & strong & 12 \\
\hline \multirow{2}{*}{5} & NO & $>80 \%$ & strong & 12 \\
\hline & PT & $>80 \%$ & strong & 12 \\
\hline \multirow{2}{*}{6} & NO & $>80 \%$ & strong & 12 \\
\hline & PT & $>80 \%$ & strong & 12 \\
\hline \multirow{2}{*}{7} & $\mathrm{NO}$ & $10-50 \%$ & strong & 6 \\
\hline & PT & $>80 \%$ & strong & 12 \\
\hline \multirow{3}{*}{8} & $\mathrm{NO}$ & $>80 \%$ & strong & 12 \\
\hline & PT & $>80 \%$ & strong & 12 \\
\hline & $\mathrm{M}(\mathrm{HEP})$ & $>80 \%$ & strong & 12 \\
\hline \multirow{6}{*}{9} & $\mathrm{NO}$ & $>80 \%$ & moderate & 8 \\
\hline & PT & $>80 \%$ & strong & 12 \\
\hline & M(PUL) & $>80 \%$ & strong & 12 \\
\hline & $\mathrm{M}(\mathrm{PUL})$ & $>80 \%$ & strong & 12 \\
\hline & $\mathrm{M}(\mathrm{HEP})$ & $>80 \%$ & strong & 12 \\
\hline & $\mathrm{M}(\mathrm{PUL})$ & $>80 \%$ & strong & 12 \\
\hline \multirow{2}{*}{10} & NO & $10-50 \%$ & moderate & 4 \\
\hline & PT & $>80 \%$ & moderate & 8 \\
\hline \multirow{2}{*}{11} & $\mathrm{NO}$ & $>80 \%$ & strong & 12 \\
\hline & PT & $>80 \%$ & moderate & 8 \\
\hline \multirow{3}{*}{12} & NO & $>80 \%$ & strong & 12 \\
\hline & PT & $>80 \%$ & strong & 12 \\
\hline & M(HEP) & $>80 \%$ & strong & 12 \\
\hline \multirow{3}{*}{13} & NO & $>80 \%$ & weak & 4 \\
\hline & PT & $>80 \%$ & strong & 12 \\
\hline & $\mathrm{M}(\mathrm{HEP})$ & & & \\
\hline
\end{tabular}

(Continued) 


\begin{tabular}{|c|c|c|c|c|}
\hline \multirow[b]{2}{*}{ Case ID } & \multirow[b]{2}{*}{ Tissue specimen } & \multicolumn{3}{|c|}{ E-cadherin protein expression } \\
\hline & & $\begin{array}{c}\% \text { positive tumor } \\
\text { cells }\end{array}$ & intensity & IRS \\
\hline \multirow{3}{*}{14} & NO & $10-50 \%$ & strong & 6 \\
\hline & $\mathrm{PT}$ & $>80 \%$ & moderate & 8 \\
\hline & M(HEP) & & & \\
\hline \multirow{4}{*}{15} & PT & $51-80 \%$ & strong & 9 \\
\hline & NO & $>80 \%$ & moderate & 8 \\
\hline & ReT & $>80 \%$ & moderate & 8 \\
\hline & $\mathrm{M}(\mathrm{HEP})$ & $51-80 \%$ & strong & 9 \\
\hline \multirow{4}{*}{16} & NO & $>80 \%$ & strong & 12 \\
\hline & PT & $>80 \%$ & strong & 12 \\
\hline & M(HEP) & $51-80 \%$ & strong & 9 \\
\hline & $\mathrm{M}(\mathrm{HEP})$ & $>80 \%$ & strong & 12 \\
\hline \multirow{3}{*}{17} & NO & $10-50 \%$ & moderate & 4 \\
\hline & PT & $>80 \%$ & moderate & 8 \\
\hline & $\mathrm{M}(\mathrm{HEP})$ & $>80 \%$ & strong & 12 \\
\hline \multirow{2}{*}{18} & NO & $>80 \%$ & strong & 12 \\
\hline & PT & $>\mathbf{8 0} \%$ & heterogeneous & $<12$ \\
\hline \multirow{2}{*}{19} & NO & $>80 \%$ & strong & 12 \\
\hline & $\operatorname{ReT}$ & $>80 \%$ & strong & 12 \\
\hline \multirow{4}{*}{20} & $\mathrm{NO}$ & $>80 \%$ & strong & 12 \\
\hline & PT & $51-80 \%$ & strong & 9 \\
\hline & $\mathrm{M}(\mathrm{HEP})$ & $>80 \%$ & strong & 12 \\
\hline & M(HEP) & $>80 \%$ & strong & 12 \\
\hline \multirow{2}{*}{21} & NO & $>80 \%$ & strong & 12 \\
\hline & PT & $>80 \%$ & moderate & 8 \\
\hline \multirow{2}{*}{22} & NO & $>80 \%$ & strong & 12 \\
\hline & PT & $51-80 \%$ & moderate & 6 \\
\hline \multirow{2}{*}{23} & NO & $>80 \%$ & strong & 12 \\
\hline & PT & $>80 \%$ & strong & 12 \\
\hline \multirow{2}{*}{24} & NO & $>80 \%$ & strong & 12 \\
\hline & PT & $>80 \%$ & strong & 12 \\
\hline \multirow{5}{*}{25} & NO & $>80 \%$ & strong & 12 \\
\hline & PT & $>80 \%$ & strong & 12 \\
\hline & M(HEP) & $>80 \%$ & strong & 12 \\
\hline & $\mathrm{M}(\mathrm{PUL})$ & $>80 \%$ & strong & 12 \\
\hline & M(PUL) & $>80 \%$ & strong & 12 \\
\hline
\end{tabular}

The table provides results of immunohistochemical analysis of E-cadherin protein expression. See text for details. Refer to Figure 8 for representative stainings (cases marked in bold in the table). 
predictive markers for response to EGFR-targeted therapy in CRC cell lines and patients.

As reported before [35-38], EGFR mRNA and protein expression was low or undetectable in most of the CRC cell lines and tissue specimens studied. If present, EGFR protein expression was non-membranous. Only one CRC case showed EGFR overexpression, most likely explained by gene amplification [35], however this was not related to EGFR-treatment response.

In CRC cell lines low EGFR expression correlated to EGFR promoter methylation, but this was not the case for CRC tissue specimens. A similar discrepancy of EGFR promoter methylation and expression in CRC tissue specimens was previously reported by Scartozzi et al. [16] and Chiadini et al. [17]. In view of this, so far EGFR methylation status $[16,17]$ or even genome-wide methylation data [39] is controversially discussed as a predictive marker for EGFR-targeted therapy.

Moreover, surprisingly EGFR protein expression itself failed as predictive marker to EGFR-targeted antibody-based therapy responses: For example, CRC patients may respond to Cetuximab even without EGFR expression [34] and - vice versa - CRC patients with EGFR-positive tumors do not exhibit higher response rates as compared to those CRC patients with EGFR-negative tumors [40, 41]. Indeed, both our in vitro and in situ analyses show that EGFR lacking tumor cells (e.g. DLD1) may be responsive to EGFR inhibition. An explanation for the positive response to EGFR-targeted inhibition in EGFR-negative tumor cells in vitro or tumor tissue specimens may be due to the dynamic nature of receptor tyrosine kinases protein stability, shuttling between cytosol and membrane as well as membranous anchoring and cleavage. Hence, we confirm previous studies in that EGFR (over)expression is not a feasible predictive marker for EGFR-targeted therapy, quite in contrast to what is seen for e.g. HER2-targeted therapy in breast cancers [42].

Furthermore, we did not detect the recently reported EGFR "resistance" mutations in EGFR exon 12 (p.G465 or p.S492). However, these were reported to be absent in KRAS wildtype tumors prior to EGFR-targeted therapy $[43,44]$ and to emerge during EGFR-targeted treatment $[30,33]$. This underlines our finding of "baseline" EGFR exon 12 wildtype sequences. Interestingly, 7 of 25 CRC cases carried a known EGFR SNP in intron 12/13 (rs1558544) but this did not correlate with EGFR-targeted treatment response. The EGFR protein structure of this EGFR variant remains unchanged according to AASsites [45] and has been detected before in Gefitinib treated lung adenocarcinoma patients without an association with survival [46].

Thus, by next investigating the current predictive marker RAS mutation status by targeted next generation sequencing (tNGS), we identified RAS mutations in CRC cell lines and tissue specimens of CRC patients treated by
EGFR-targeted therapy. In fact, RAS mutations were seen in both responding and non-responding CRC cell lines as well as in CRC cases with long and short overall survival. The responding cell line DLD1 and the intermediate responding cell line HCT116 both carried a KRAS codon p.G13 mutation, which was in fact reported previously as being a "beneficial" mutation associated with Cetuximab response by others before [47-49]. This RAS mutation was not detected in the CRC cases. The CRC cases mostly harbored a RAS exon 3 codon p.Q61 mutation, which at the time of treatment of this retrospective CRC cohort was not yet included into routine diagnostic and clinical guidelines. Of the $8 / 25$ patients with RAS mutations $5 / 8$ showed progressive disease, for $2 / 8$ no information about response rate was available, further underlying the concept of comprehensive RAS testing [7, 50]. However, RAS testing alone cannot explain the poor response in other CRC cases.

Hence, by tNGS we next screened for alterations in genes coding for receptor tyrosine kinases, RAS/ MAPK and PIK3/AKT signaling pathways, which may bypass EGFR inhibition by antibody-based therapies. We detected alterations in RTK up to 59.6\%, RAS/MAPK in up to $38.3 \%$ and PIK3/AKT in up to $27.7 \%$. No direct correlation was found between these mutations and response to EGFR-targeted therapy as evaluated by overall survival. Indeed, combination of mutations in these downstream signaling pathways were shown to influence direct (B)RAF inhibition $[51,52]$ rather than EGFR-targeted therapy.

Of interest were the detected PIK3CA mutation patterns. PIK3CA is frequently mutated in several solid tumors [8] and mostly occur in PIK3CA exon 9 within the coding region for the helical domain and exon 20 within the coding region for the kinase domain [53], which was also the case in our study (Supplementary Figure 4). The PIK3CA exon 9 p.E545K as such leads to a change in charge of the protein [53], whereas the PIK3CA p.H1047R mutations results in constitutive activation [54]. Whilst PIK3CA exon 9 mutation may be without gross functional consequences, the activating exon 20 mutation may result in resistance to up-stream EGFR-targeted therapy. Indeed, the CRC cell line DLD1 responding to Cetuximab exhibited two PIK3CA exon 9 mutations (p.E545K, p.D549N), PIK3CA exon 20 mutations (p.H1047R) were only observed in CRC cases with progressive disease and short overall survival under EGFR-targeted therapy. A direct predictive value of PIK3CA mutations for Cetuximab resistance is still controversially discussed [ 55 , 56], but PIK3CA mutations were reported by others to e.g. also significantly correlate with lower progression free and overall survival of CRC patients [7].

Besides direct EGFR signaling associated genes, the most frequent mutations observed in CRC cell lines and cases were ATM, SMAD4, KDR, ErBB4 and 
Table 6: A matrix for response prediction to EGFR-targeted therapy in CRC

\begin{tabular}{|c|c|c|c|c|c|c|c|c|c|}
\hline $\begin{array}{c}\text { EGFR-targeted } \\
\text { Tx response }\end{array}$ & ID\# & MSI & CIMP & RAS & BRAF & PIK3CA & ATM & $\begin{array}{c}\text { EGFR } \\
\text { protein }\end{array}$ & $\begin{array}{c}\text { E-cadherin } \\
\text { protein }\end{array}$ \\
\hline \multirow{8}{*}{ Responders } & DLD1 & + & + & mut. & wt & mut. & wt & $(+)$ & +++ \\
\hline & 3 & - & - & wt & wt & mut. & wt & 0 & 12 \\
\hline & 8 & - & - & wt & wt & mut. & wt & 0 & 12 \\
\hline & 15 & - & - & wt & wt & wt & wt & 0 & 9 \\
\hline & 1 & - & - & mut. & wt & wt & wt & 0 & 12 \\
\hline & 23 & - & - & mut. & wt & wt & wt & 0 & 12 \\
\hline & 9 & - & - & wt & wt & wt & wt & 0 & 12 \\
\hline & 6 & - & - & wt & wt & wt & wt & 0 & 12 \\
\hline \multirow{9}{*}{$\begin{array}{l}\text { Intermediate } \\
\text { responders }\end{array}$} & НCT116 & + & + & mut. & wt & mut. & wt & $(+)$ & + \\
\hline & LS174T & + & - & mut. & wt & mut. & wt & ++ & ++ \\
\hline & Caco-2 & - & - & wt & wt & wt & wt & +++ & + \\
\hline & HT29 & - & + & wt & mut. & wt & mut. & ++ & ++ \\
\hline & 17 & - & n.d. & wt & wt & wt & mut. & 0 & 8 \\
\hline & 13 & - & - & wt & wt & wt & wt (mut.) & 0 & 12 \\
\hline & 4 & - & - & wt & wt & wt & wt & 0 & 12 \\
\hline & 10 & - & - & wt & wt & wt & wt & 0 & 8 \\
\hline & 16 & - & - & mut. & wt & wt (mut.) & wt (mut.) & 1 & 12 \\
\hline \multirow{7}{*}{ Non responders } & SW480 & - & - & mut. & wt & wt & wt & - & $(+)$ \\
\hline & RKO & + & + & wt & mut. & mut. & mut. & - & $(+)$ \\
\hline & 14 & - & - & mut. & wt & wt (mut.) & wt & 0 & 8 \\
\hline & 18 & + & + & wt & mut. & $\mathbf{w t}$ & wt & 0 & $\begin{array}{l}<12 \\
\text { heterogeneous }\end{array}$ \\
\hline & 21 & - & - & mut. & wt & wt & wt & 0 & 8 \\
\hline & 2 & - & - & mut. & wt & wt (mut.) & wt (mut.) & 0 & 8 \\
\hline & 11 & - & - & wt & wt & wt & wt & 0 & 8 \\
\hline \multirow{8}{*}{ unknown } & 5 & - & - & wt & wt & wt & wt & 0 & 12 \\
\hline & 7 & - & - & mut. & wt & wt & wt & 0 & 12 \\
\hline & 12 & - & - & mut. & wt & mut. & wt & 0 & 12 \\
\hline & 19 & - & + & wt & wt & wt & wt & 0 & 12 \\
\hline & 20 & - & - & wt & wt & wt & wt & 0 & 9 \\
\hline & 22 & - & - & mut. & wt & wt & wt & 0 & 12 \\
\hline & 24 & - & - & wt & wt & wt & wt & 0 & 12 \\
\hline & 25 & - & - & wt & wt & wt & mut. & 3 & 12 \\
\hline
\end{tabular}

The table shows alterations of primary tumors (and in recurrent tumors or metastases, parentheses). Responders $>12$ months overall survival, intermediate responders $>6$ to 12 months overall survival, non-responders $=/<6$ months overall survival. mut =mutated, wt=wildtype; n.d.= not determined; “+”= positive; “_" = negative. 
FBXW7, as reported by others for CRC before [57, 58]. Indeed, SMAD4, ErBB4 and FBXW7 mutations appear to confer treatment resistance to Cetuximab [5]. However, this association was not seen in our study, with e.g. SMAD4 (59), ErBB4 (39) and FBXW7 (38) mutations being present in both EGFR-targeted therapy responders and non-responders. In contrast, our study rather suggests ATM mutations to be involved in treatment resistance to Cetuximab. ATM (ataxia telangiectasia mutated) belongs to the PI3/PI4-kinase family, is able to form a complex with EGFR [58], causes phosphorylation of AKT [59] and was suggested as a therapeutic target in cancer [12]. The possible functional consequences of the here detected ATM mutations in the EGFR pathway still need to be elucidated, but are beyond the scope of this study.

Irrespective of the comprehensive analyses of EGFR and mutations in associated signaling pathways, other mechanisms may influence EGFR functionality and its inhibition by therapeutic agents. As such, E-cadherin plays a role in EGF receptor recruitment and activation [59, 60]. Moreover, it was shown that cells loosing E-cadherin are able to circumvent the classical EGFR signaling and therefore acquire resistance to treatment with antibodies against EGFR [24]. Finally, restoring E-cadherin expression is postulated to increase the sensitivity to antiEGFR treatment [61]. Indeed, in our in vitro experiments down-regulation of E-cadherin by siRNA in DLD1 cells (high E-cadherin expressing cells, Cetuximab responders) abrogated their response to Cetuximab. Moreover, two of the non-responding CRC cell lines had only weak and/or cytoplasmic E-cadherin expression, lacking the mature E-cadherin protein. One hypothesis of how this E-cadherin driven resistance mechanism may act, is that E-cadherin is shed from the tumor cells in a soluble form, which - as shown in in vitro model systems [22] - may then activate EGFR promoting cell survival [62]. Our present data does not directly confirm that E-cadherin cleavage and presence of elevated levels of soluble E-cadherin are responsible for Cetuximab resistance, but it clearly shows that dynamic regulation of E-cadherin expression and intracellular localization, respective E-cadherin maturity does have an impact on CRC cells responses to Cetuximab. This was also seen in situ, were we found 9/25 CRC cases which lacked strong and complete membranous E-cadherin expression in tumor cells. This is in part in accordance with a recent study [23], which investigated 229 not therapy-preselected CRC patients and only detected $4.3 \%$ of cases being E-cadherin negative. Examining the precise dynamic nature of E-cadherin expression and subcellular localization and/or its cleavage and soluble form in formalin-fixed and paraffinembedded tissue specimens is currently technically not possible. Nevertheless, our data clearly demonstrates that a loss of E-cadherin expression is linked to EGFR-targeted therapy non-responder CRC cell lines and cases.

In summary, our study comprehensively analyses both CRC cell lines and tissue specimens for known and novel putative predictive markers of EGFR-targeted therapy responses and is the first to identify ATM mutations and E-cadherin expression as potential novel supportive predictive markers for EGFR-targeted therapy.

\section{MATERIALS AND METHODS}

\section{Cell lines}

All cell lines (Caco-2, HT29, SW480, DLD1, HCT116, LS174T, RKO) were cultured in a humidified atmosphere $\left(37^{\circ} \mathrm{C}, 5 \% \mathrm{CO}_{2}\right)$ in their corresponding medium supplemented with $10 \%$ fetal calf serum (Life Technologies) and 1\% Glutamin (GE Healthcare). Caco-2, LS174T, RKO and SW480 were cultured in DMEM, high glucose, DLD1 in RPMI, HCT116 and HT29 in McCoys 5A medium (all Life Technologies). All CRC cell lines were screened for mycoplasma contamination using Venor GeM Classic Mycoplasma Detection Kit (Minerva biolabs) and DNA fingerprinting was performed for all seven cell lines at the Leibniz Institute DSMZ, Braunschweig, Germany.

\section{Cell viability assay}

The effect of Cetuximab (MerckSerono) on cell proliferation of colorectal cancer cell lines (Caco-2, HT29, SW480, DLD1, HCT116, LS174T, RKO) was measured using Cell titer $96^{\circledR}$ Aqueous One Solution Cell Proliferation Assay (MTS) (Promega). $2.0-3.5 \times 10^{3}$ cells/well were seeded in triplicates on a 96 well plate and allowed to adhere over night at $37^{\circ} \mathrm{C}$ in a $5 \% \mathrm{CO}_{2}$ humidified atmosphere in their corresponding medium. The cells were treated with Cetuximab $(0.1,1,10,50,100 \mu \mathrm{g} / \mathrm{ml})$ and $0.9 \% \mathrm{NaCl}$ solution as control for $72 \mathrm{~h}$. Then, $20 \mu \mathrm{l}$ of MTS solution was added and the absorbance was measured at 490nm with a microplate reader (Tecan) after additional $2 \mathrm{~h}$ incubation at $37^{\circ} \mathrm{C}$. Proliferation was recorded as $\%$ of control.

\section{Antibody-dependent cellular cytotoxicity (ADCC)}

The antibody-dependent cellular cytotoxicity assay was performed according to Fichter et al. [63]. Peripheral blood mononuclear cells (PBMCs) were isolated using Pancoll lymphocyte separation medium (PAN-Biotech $\mathrm{GmbH}$ ). PBMCs were incubated with target cells (Caco2, HT29, SW480, DLD1, HCT116, LS174T, RKO) at various effector-to-target ratios $(1: 1,1: 2.5,1: 5,1: 10$, $1: 20,1: 40)$ in triplicates in medium alone or in medium in the presence of $10 \mu \mathrm{g} / \mathrm{ml}$ Cetuximab (MerckSerono). After 4h, cytotoxicity was measured using the CytoTox 96® Non-Radioactive Cytotoxicity Assay (Promega). The absorbance was recorded at 490nm using a 96-well plate reader (Tecan). Percentage of cytotoxicity was calculated using the following equation: \%cytotoxicity $=$ (experimental - effector spontaneous - target spontaneous) / (target maximum - target spontaneous) x 100. 


\section{Down-regulation of E-cadherin by siRNA}

As adapted from the siRNA approach used by us before [64] $1.7 \times 10^{5}$ DLD1 cells were transfected with either 100nM E-cadherin siRNA (SMARTpool: si Genome CDH1siRNA, GE Dharmacon) or Silencer negative control siRNA, Thermo Fisher Scientific using Dharma Fect2 Transfection Reagent, GE Dharmacon. Transfection control was with DharmaFECT 2 Transfektion Reagent, GE Dharmacon.

Cells were investigated at $72 \mathrm{~h}$ post siRNA treatment for E-cadherin protein levels by Western Blot and were subjected to ADCC at $72 \mathrm{~h}$ post siRNA treatment.

\section{Immunofluorescence staining of colorectal cancer cells}

$3 \times 10^{4}$ cells/well were seeded onto a 24 well plate, covered with sterile coverslides and allowed to adhere overnight in their corresponding medium. Cells were fixed in $2 \%$ formalin for $20 \mathrm{~min}$ at room temperature (RT), permeabilized for $10 \mathrm{~min}$ at $4{ }^{\circ} \mathrm{C}$ in $0.5 \%$ Triton-X100/ PBS, blocked for $1 \mathrm{~h}$ at RT in 5\% normal goat serum $/ 0.3 \%$ Triton-X100/PBS. E-cadherin antibody (1:200, clone 24E10, Cell signaling) and normal rabbit IgG isotype control (Cell signaling) were incubated overnight at $4{ }^{\circ} \mathrm{C}$. After removing the antibodies and washing with 1x PBS the secondary antibody goat anti-rabbit IgG A488 (1:200) was added and incubated for $1 \mathrm{~h}$ in the dark. The cells were washed again and were counterstained with vectashield mounting medium with DAPI (vector laboratories). Pictures were taken using a fluorescence microscope (Axioplan 2 imaging with apotome system, Carl Zeiss).

\section{Cell lysis and western blotting}

Total protein lysates were prepared using Qproteome Mammalian Protein Prep Kit (Qiagen). The following antibodies were used for immunodetection: E-cadherin (1:2000, clone 24E10, Cell signaling), $\beta$-Actin (1:5000, Sigma Aldrich). Bands were quantified by using fusion capt Advance FX7 software (Vilber).

\section{Detection of soluble E-cadherin by ELISA}

Soluble E-cadherin was measured in cell culture supernatants using Quantikine ELISA (human E-cadherin immunoassay, R\&D Systems) according to the manufacturer's instructions. Cell culture supernatants of seven colorectal cancer cell lines were harvested after $48 \mathrm{~h}$ and $72 \mathrm{~h}$. Three independent experiments were performed and data given as mean $+/$ - standard deviation.

\section{Patients and tissue specimens}

This study included 25 colorectal cancer patients, of whom primary or recurrent tumors as well as liver or lung metastases in 12/25 of cases were examined. 23/25 CRC cases were previously tested for KRAS exon 2 mutations at the Institute of Surgical Pathology, Medical Center University of Freiburg, Freiburg, Germany. All patients were treated with Cetuximab and/or Panitumumab, 22/25 received concurrent chemotherapy. All patients underwent surgery at the Department of Surgery, Medical Center University of Freiburg, Freiburg, Germany between 2002 and 2014.

Tissue specimens were formalin-fixed and paraffinembedded (FFPE). Normal colonic epithelial cells were derived from tissue blocks of the resection margin, whereas primary tumors and metastases were derived from central tumor mass. The use of tissue specimens was approved by the local ethics institution (\#251/04/07/09, \#66/07 and \#191/13 Ethik-Kommission, University of Freiburg, Germany). The clinico-pathological characteristics of the colorectal cancer patients are summarized in Table 2.

\section{Immunohistochemistry staining}

Serial sections $(2 \mu \mathrm{M})$ of formalin-fixed and paraffinembedded (FFPE) tissues were used for EGFR and E-cadherin staining. The tissue sections were incubated at $37^{\circ} \mathrm{C}$ (EGFR) or $58^{\circ} \mathrm{C}$ (E-cadherin) overnight, deparaffinized with xylene and rehydrated with ethanol in decreasing concentrations $(96 \%, 70 \%)$. After antigen retrieval (EGFR: digestion with $0.05 \%$ proteinase $\mathrm{K}$ for $5 \mathrm{~min}$; E-cadherin $\mathrm{NCH}-38$ : pH6.1 buffer by pressure cooker/sico for 2min; E-cadherin 24E10: pH6.1 buffer, pressure cooker for $5 \mathrm{~min}$ ), tissue sections were stained with diluted antibodies to EGFR (mouse monoclonal, clone H11, 1:500, $1 \mathrm{hr}$, DakoCytomation/Agilent) and to two different antibodies E-cadherin (mouse monoclonal, clone NCH-38, 1:1000, 30min, DakoCytomation/Agilent; rabbit monoclonal, clone 24E10, 1:100, 30min, Cell Signaling Technology,) followed by the Dako REAL Detection System (alkaline phosphatase/RED, rabbit/ mouse, Dako) for EGFR and the EnVision ${ }^{\mathrm{TM}}$ Flex System for E-cadherin.

All steps were performed on an autostainer (Dako). Scoring for EGFR was according to Fichter et al. [63]. Score $0=$ negative expression/incomplete membranous in $\leq 10 \%$ tumor cells, score $1=$ partial membranous expression in $>10 \%$ tumor cells, score $2=$ weak, but complete membranous expression in $>10 \%$ tumor cells and score $3=$ strong and complete membranous expression in $>10 \%$ tumor cells. Scoring for E-cadherin was performed according to Kang et al. [23], with an immunoreactive score (IRS) that combines $\%$ immunopositive cells $(0=0 \%, 1=<10 \%, 2=10-50 \%$, $3=51-80 \%, 4>80 \%)$ with staining intensity $(0=$ no staining, $1=$ weak, $2=$ moderate, $3=$ strong) resulting in overall IRS scores from 0-12. IHC stainings were evaluated by two independend observers (ALG, LL). 


\section{Microdissection, DNA and RNA isolation}

Tumor cells were marked for all tissue specimens on newly prepared hematoxylin-eosin sections by a qualified pathologist (LL) for subsequent microdissection of tumor cells under morphological control. Tissue slides were deparaffinized with xylene and rehydrated with ethanol in decreasing concentrations $(100 \%, 90 \%, 70 \%, 50 \%)$, briefly stained in hematoxylin and digested overnight. DNA was isolated using the QIAamp DNA FFPE Tissue Kit and RNA was isolated using the RNeasy FFPE Kit. DNA and RNA of patient \#25 were available from a previous isolation using the AllPrep DNA/RNA FFPE Kit. Total DNA of cell lines was isolated using DNeasy Blood \& Tissue Kit and total RNA was isolated using the RNeasy Mini Kit. All isolation kits were from Qiagen and isolations were according to manufacturer's instructions.

\section{Microsatellite instability testing (MSI)}

For MSI testing, a new multiplex PCR protocol was established with modifications to a previous protocol [65]. In brief, 25- $\mu$ l PCR multiplex fluorescent reaction mix was composed of $1 \times$ PCR buffer (Qiagen), $2 \mathrm{mM} \mathrm{MgCl}_{2}$ (Qiagen), 0.4 mM dNTPs (ThermoFisher Scientific), TaqPolymerase 1.25 units (Qiagen) and primer sets FAM or VIC-labeled in the following concentrations: $0.1 \mu \mathrm{M}$ (Bat25-F-NED, Bat26-F-VIC, D2S123-F-VIC, D5S346FFAM), 0.2 $\mu$ M (Bat25-R, Bat26-R, D2S123-R, D5S346-R, D17S250-F-FAM), 0.4 $\mu$ M (D17S250-R). 100ng normal and tumor DNA were used for PCR, which was performed in a Biometra Professional TRIO Thermocycler according to cycling conditions of Berg et al [65]. Fluorescently labeled PCR products were detected using ABI PRISM 3130xl Genetic Analyzer and GeneMapper 4.0 software for data analysis.

\section{CpG island methylator phenotype classification and analysis of EGFR promoter methylation}

For determination of $\mathrm{CpG}$ island methylator phenotype (CIMP) and EGFR promoter methylation, DNA was bisulfite converted using the EpiTect Fast Bisulfite Conversion Kit, according to manufacturer's instructions (Qiagen). For each gene specific PCR reaction, $20 \mathrm{ng}$ of bisulfite converted DNA was used. CIMP type definition was performed according to modified protocols by Weisenberger et al. [66], Zlobec et al. [67] and Ogino et al. [68]. Methylation of five CIMP-related genes RUNX3, CACNA1G, EPM2AIP1/ MLH1, NEUROG1 and CRABP1 was measured using the following PyroMark $\mathrm{CpG}$ assays: $\mathrm{Hs}$ RUNX3_08_PM (PM00000161), Hs_CACNA1G_02 PM (PM00064736), Hs_EPM2AIP1/MLH1_01_PM (PM00104832), Hs_NEUROG1_01_PM (PM00023632) Hs_CRABP1_02_PM (PM00059605) (Qiagen). Data was analyzed using the PyroMark Q24 Software
(Qiagen). Three to five $\mathrm{CpG}$ sites were evaluated per gene. A gene was classified as methylated, if the difference in mean methylation between tumor and the corresponding normal tissue was $\geq 19 \%$. A case was defined as CIMP positive, if $\geq 3 / 5$ of analyzed CIMPrelated genes were methylated and CIMP negative otherwise. EGFR methylation analysis of three $\mathrm{CpG}$ sites was performed as above using the Hs_EGFR_02 PM (PM00030569) PyroMark CpG assay (Qiagen).

\section{Next generation sequencing}

As reported by us before [69], DNA quality was measured using FFPE QC kit and libraries were prepared using the TruSeq Amplicon Cancer Panel (48 cancer related genes) (both Illumina). Quantity and quality of libraries were examined using the Bioanalyzer 2100 system (Agilent Technologies) and DNAs were pooled for sequencing on the MiSeq (Illumina). Mutations, passing the filter, were listed using VariantStudio (Illumina). Missense, stop gained and frameshift mutations displaying read depth $>100$, alt variant frequency $>10$ and occurring inside the gene were incorporated in the study.

\section{EGFR mutation analysis by dideoxy sequencing}

EGFR Exon 12 mutations at codon G465 and S492 were analyzed using the following primers. G465: For-5'-TTTCTCTTGCAGTCGTCAGC-3', rev5'-TGCAGCTGTTTTCACCTCTG-3'. S492R: For-5'GTGCTATGCAAATACAATAAACTGG-3' and rev5'GGACCCATTAGAACCAACTCC-3' [43] 100 ng of DNA were amplified using $20 \mu \mathrm{M} /$ primer in a first PCR. The PCR products were purified using QIAquick PCR purification kit according to manufacturer's instructions (Qiagen) and a second cycle-PCR for sequencing was performed. For dye terminator removal, DNA products were cleaned up via DyeEx 2.0 Spin Kit (Qiagen) and sequenced on an ABI 3130xl Genetic Analyzer (ThermoFisher Scientific, Waltham, United States).

\section{EGFR mRNA expression}

EGFR mRNA expression was measured by q-RT-PCR. First, 750 ng RNA was transcribed in cDNA using M-MLV reverse transcriptase (Invitrogen, Carlsbad, United States). Next, cDNA was amplified with primers and probes for EGFR (For-5'- GCCTCCAGAGGATGTTCAATAA-3', rev5'-TGAGGGCAATGAGGACATAAC-3', probe 5'-TGAG GTGGTCCTTGGGAATTTGGA-3') and the reference gene TBP (for-5'-GCCCGAAACGCCGAATAT-3', rev-5'-C CGTGGTTCGTGGCTCTCT-3', probe 5'-ATCCCAAGC GGTTTGCTGCGG-3') [70]. The analysis was performed on a 7900HT fast real time PCR system (Applied Biosystems). Relative expression of the genes of interest was calculated using the $2^{-\Delta \Delta C T}$-method. $[71,72]$. Besides unknown samples, 
a universal human reference RNA (Agilent Technologies) was transcribed in cDNA and used as reference to calculate the relative fold change of EGFR mRNA expression.

\section{Statistical analysis}

Statistical analysis was performed using JMP version 12 statistical software. Survival distribution was estimated by the Kaplan-Meier method. Significant differences were evaluated by log-rank test and a level of 0.05 was considered statistically significant. Overall survival (OS) was defined as the interval between the start of Cetuximab/Panitumumab treatment to death.

\section{ACKNOWLEDGMENTS}

The authors acknowledge the excellent laboratory work of Bianca Riedel, Fabian Beier, Marion Kunz and Xenia Ungefug .The authors thank Prof. Dr. A. Hecht for providing CRC cell lines LS174T and SW480, Dr. Tilman Brummer for providing RKO cells.

\section{CONFLICTS OF INTEREST}

The authors declare no conflicts of interest.

\section{FUNDING}

This study was funded by the German Consortium for Translational Cancer Research (DKTK Program Molecular Diagnostics) and in part by the Mushett Family Foundation (Chester, NJ, USA) (grants to SL, MW).

\section{REFERENCES}

1. Siegel R, Desantis C, Jemal A. Colorectal cancer statistics, 2014. CA Cancer J Clin. 2014; 64:104-117.

2. Tran NH, Cavalcante LL, Lubner SJ, Mulkerin DL, LoConte NK, Clipson L, Matkowskyj KA, Deming DA. Precision medicine in colorectal cancer: the molecular profile alters treatment strategies. Therapeutic advances in medical oncology. 2015; 7:252-262.

3. Lievre A, Bachet JB, Le Corre D, Boige V, Landi B, Emile JF, Cote JF, Tomasic G, Penna C, Ducreux M, Rougier P, Penault-Llorca F, Laurent-Puig P. KRAS mutation status is predictive of response to cetuximab therapy in colorectal cancer. Cancer research. 2006; 66:3992-3995.

4. Lievre A, Bachet JB, Boige V, Cayre A, Le Corre D, Buc E, Ychou M, Bouche O, Landi B, Louvet C, Andre T, Bibeau F, Diebold MD, Rougier P, Ducreux M, Tomasic G, et al. KRAS mutations as an independent prognostic factor in patients with advanced colorectal cancer treated with cetuximab. Journal of clinical oncology. 2008; 26:374-379.

5. Lupini L, Bassi C, Mlcochova J, Musa G, Russo M, Vychytilova-Faltejskova P, Svoboda M, Sabbioni S,
Nemecek R, Slaby O, Negrini M. Prediction of response to anti-EGFR antibody-based therapies by multigene sequencing in colorectal cancer patients. BMC cancer. $2015 ; 15: 808$.

6. Eklof V, Wikberg ML, Edin S, Dahlin AM, Jonsson BA, Oberg A, Rutegard J, Palmqvist R. The prognostic role of KRAS, BRAF, PIK3CA and PTEN in colorectal cancer. British journal of cancer. 2013; 108:2153-2163.

7. De Roock W, Claes B, Bernasconi D, De Schutter J, Biesmans B, Fountzilas G, Kalogeras KT, Kotoula V, Papamichael D, Laurent-Puig P, Penault-Llorca F, Rougier P, Vincenzi B, Santini D, Tonini G, Cappuzzo F, et al. Effects of KRAS, BRAF, NRAS, and PIK3CA mutations on the efficacy of cetuximab plus chemotherapy in chemotherapy-refractory metastatic colorectal cancer: a retrospective consortium analysis. The Lancet Oncology. 2010; 11:753-762.

8. Samuels Y, Wang Z, Bardelli A, Silliman N, Ptak J, Szabo S, Yan H, Gazdar A, Powell SM, Riggins GJ, Willson JK, Markowitz S, Kinzler KW, Vogelstein B, Velculescu VE. High frequency of mutations of the PIK3CA gene in human cancers. Science. 2004; 304:554.

9. Corcoran RB, Atreya CE, Falchook GS, Kwak EL, Ryan DP, Bendell JC, Hamid O, Messersmith WA, Daud A, Kurzrock R, Pierobon M, Sun P, Cunningham E, Little S, Orford K, Motwani M, et al. Combined BRAF and MEK Inhibition With Dabrafenib and Trametinib in BRAF V600Mutant Colorectal Cancer. Journal of clinical oncology. 2015; 33:4023-4031.

10. Abraham RT. Cell cycle checkpoint signaling through the ATM and ATR kinases. Genes \& development. 2001; 15:2177-2196.

11. Powell SN, DeFrank JS, Connell P, Eogan M, Preffer F, Dombkowski D, Tang W, Friend S. Differential sensitivity of p53(-) and p53(+) cells to caffeine-induced radiosensitization and override of G2 delay. Cancer research. 1995; 55:1643-1648.

12. Weber AM, Ryan AJ. ATM and ATR as therapeutic targets in cancer. Pharmacology \& therapeutics. 2015; 149:124-138.

13. Slamon DJ, Leyland-Jones B, Shak S, Fuchs H, Paton V, Bajamonde A, Fleming T, Eiermann W, Wolter J, Pegram M, Baselga J, Norton L. Use of chemotherapy plus a monoclonal antibody against HER2 for metastatic breast cancer that overexpresses HER2. The New England journal of medicine. 2001; 344:783-792.

14. Troiani T, Martinelli E, Napolitano S, Vitagliano D, Ciuffreda LP, Costantino S, Morgillo F, Capasso A, Sforza V, Nappi A, De Palma R, D’Aiuto E, Berrino L, Bianco $\mathrm{R}$, Ciardiello F. Increased TGF-alpha as a mechanism of acquired resistance to the anti-EGFR inhibitor cetuximab through EGFR-MET interaction and activation of MET signaling in colon cancer cells. Clinical cancer research. 2013; 19:6751-6765.

15. Irizarry RA, Ladd-Acosta $\mathrm{C}$, Wen $\mathrm{B}, \mathrm{Wu} \mathrm{Z}$, Montano C, Onyango P, Cui H, Gabo K, Rongione M, Webster 
M, Ji H, Potash JB, Sabunciyan S, Feinberg AP. The human colon cancer methylome shows similar hypo- and hypermethylation at conserved tissue-specific $\mathrm{CpG}$ island shores. Nature genetics. 2009; 41:178-186.

16. Scartozzi M, Bearzi I, Mandolesi A, Giampieri R, Faloppi L, Galizia E, Loupakis F, Zaniboni A, Zorzi F, Biscotti T, Labianca R, Falcone A, Cascinu S. Epidermal growth factor receptor (EGFR) gene promoter methylation and cetuximab treatment in colorectal cancer patients. British journal of cancer. 2011; 104:1786-1790.

17. Chiadini E, Scarpi E, Passardi A, Calistri D, Valgiusti M, Saragoni L, Zoli W, Amadori D, Ulivi P. EGFR methylation and outcome of patients with advanced colorectal cancer treated with cetuximab. Oncology letters. 2015; 9:1432-1438.

18. Takeichi M. Cadherin cell adhesion receptors as a morphogenetic regulator. Science. 1991; 251:1451-1455.

19. Onder TT, Gupta PB, Mani SA, Yang J, Lander ES, Weinberg RA. Loss of E-cadherin promotes metastasis via multiple downstream transcriptional pathways. Cancer research. 2008; 68:3645-3654.

20. Dorudi S, Sheffield JP, Poulsom R, Northover JM, Hart IR. E-cadherin expression in colorectal cancer. An immunocytochemical and in situ hybridization study. The American journal of pathology. 1993; 142:981-986.

21. Bremnes RM, Veve R, Gabrielson E, Hirsch FR, Baron A, Bemis L, Gemmill RM, Drabkin HA, Franklin WA. Highthroughput tissue microarray analysis used to evaluate biology and prognostic significance of the E-cadherin pathway in non-small-cell lung cancer. Journal of clinical oncology. 2002; 20:2417-2428.

22. Patil PU, D'Ambrosio J, Inge LJ, Mason RW, Rajasekaran AK. Carcinoma cells induce lumen filling and EMT in epithelial cells through soluble E-cadherin-mediated activation of EGFR. Journal of cell science. 2015; 128:4366-4379.

23. Kang H, Min BS, Lee KY, Kim NK, Kim SN, Choi J, Kim H. Loss of E-cadherin and MUC2 expressions correlated with poor survival in patients with stages II and III colorectal carcinoma. Annals of surgical oncology. 2011; 18:711-719.

24. Nakamoto K, Nagahara H, Maeda K, Noda E, Inoue T, Yashiro M, Nishiguchi Y, Ohira M, Hirakawa K. Expression of E-cadherin and KRAS mutation may serve as biomarkers of cetuximab-based therapy in metastatic colorectal cancer. Oncology letters. 2013; 5:1295-1300.

25. Nikolova DA, Asangani IA, Nelson LD, Hughes DP, Siwak DR, Mills GB, Harms A, Buchholz E, Pilz LR, Manegold $\mathrm{C}$, Allgayer H. Cetuximab attenuates metastasis and u-PAR expression in non-small cell lung cancer: u-PAR and E-cadherin are novel biomarkers of cetuximab sensitivity. Cancer research. 2009; 69:2461-2470.

26. Black PC, Brown GA, Inamoto T, Shrader M, Arora A, Siefker-Radtke AO, Adam L, Theodorescu D, Wu X, Munsell MF, Bar-Eli M, McConkey DJ, Dinney CP.
Sensitivity to epidermal growth factor receptor inhibitor requires E-cadherin expression in urothelial carcinoma cells. Clinical cancer research. 2008; 14:1478-1486.

27. Ahmed D, Eide PW, Eilertsen IA, Danielsen SA, Eknaes M, Hektoen M, Lind GE, Lothe RA. Epigenetic and genetic features of 24 colon cancer cell lines. Oncogenesis. 2013; 2:e71.

28. Lo Nigro C, Ricci V, Vivenza D, Monteverde M, Strola G, Lucio F, Tonissi F, Miraglio E, Granetto C, Fortunato M, Merlano MC. Evaluation of antibody-dependent cellmediated cytotoxicity activity and cetuximab response in KRAS wild-type metastatic colorectal cancer patients. World journal of gastrointestinal oncology. 2016; $8: 222-230$.

29. Kimura H, Sakai K, Arao T, Shimoyama T, Tamura T, Nishio K. Antibody-dependent cellular cytotoxicity of cetuximab against tumor cells with wild-type or mutant epidermal growth factor receptor. Cancer science. 2007; 98:1275-1280.

30. Montagut C, Dalmases A, Bellosillo B, Crespo M, Pairet S, Iglesias M, Salido M, Gallen M, Marsters S, Tsai SP, Minoche A, Seshagiri S, Serrano S, Himmelbauer H, Bellmunt J, Rovira A, et al. Identification of a mutation in the extracellular domain of the Epidermal Growth Factor Receptor conferring cetuximab resistance in colorectal cancer. Nature medicine. 2012; 18:221-223.

31. Montero AJ, Diaz-Montero CM, Mao L, Youssef EM, Estecio M, Shen L, Issa JP. Epigenetic inactivation of EGFR by $\mathrm{CpG}$ island hypermethylation in cancer. Cancer biology \& therapy. 2006; 5:1494-1501.

32. Atreya CE, Corcoran RB, Kopetz S. Expanded RAS: refining the patient population. Journal of clinical oncology. 2015; 33:682-685.

33. Braig F, Marz M, Schieferdecker A, Schulte A, Voigt M, Stein A, Grob T, Alawi M, Indenbirken D, Kriegs M, Engel E, Vanhoefer U, Grundhoff A, et al. Epidermal growth factor receptor mutation mediates cross-resistance to panitumumab and cetuximab in gastrointestinal cancer. Oncotarget. 2015; 6:12035-12047. doi: 10.18632/ oncotarget. 3574.

34. Chung KY, Shia J, Kemeny NE, Shah M, Schwartz GK, Tse A, Hamilton A, Pan D, Schrag D, Schwartz L, Klimstra DS, Fridman D, Kelsen DP, Saltz LB. Cetuximab shows activity in colorectal cancer patients with tumors that do not express the epidermal growth factor receptor by immunohistochemistry. Journal of clinical oncology. 2005; 23:1803-1810.

35. Ooi A, Takehana T, Li X, Suzuki S, Kunitomo K, Iino H, Fujii H, Takeda Y, Dobashi Y. Protein overexpression and gene amplification of HER-2 and EGFR in colorectal cancers: an immunohistochemical and fluorescent in situ hybridization study. Modern pathology. 2004; 17:895-904.

36. Kountourakis P, Pavlakis K, Psyrri A, Rontogianni D, Xiros N, Patsouris E, Pectasides D, Economopoulos T. Clinicopathologic significance of EGFR and Her-2/neu 
in colorectal adenocarcinomas. Cancer journal. 2006; 12:229-236.

37. Mahipal A, McDonald MJ, Witkiewicz A, Carr BI. Cell membrane and cytoplasmic epidermal growth factor receptor expression in pancreatic ductal adenocarcinoma. Medical oncology. 2012; 29:134-139.

38. Pu YS, Huang CY, Kuo YZ, Kang WY, Liu GY, Huang AM, Yu HJ, Lai MK, Huang SP, Wu WJ, Chiou SJ, Hour TC. Characterization of membranous and cytoplasmic EGFR expression in human normal renal cortex and renal cell carcinoma. Journal of biomedical science. 2009; 16:82.

39. Ouchi K, Takahashi S, Yamada Y, Tsuji S, Tatsuno K, Takahashi H, Takahashi N, Takahashi M, Shimodaira $\mathrm{H}$, Aburatani H, Ishioka C. DNA methylation status as a biomarker of anti-epidermal growth factor receptor treatment for metastatic colorectal cancer. Cancer science. 2015; 106:1722-1729.

40. Cunningham D, Humblet Y, Siena S, Khayat D, Bleiberg H, Santoro A, Bets D, Mueser M, Harstrick A, Verslype C, Chau I, Van Cutsem E. Cetuximab monotherapy and cetuximab plus irinotecan in irinotecan-refractory metastatic colorectal cancer. The New England journal of medicine. 2004; 351:337-345.

41. Saltz LB, Meropol NJ, Loehrer PJ, Sr., Needle MN, Kopit J, Mayer RJ. Phase II trial of cetuximab in patients with refractory colorectal cancer that expresses the epidermal growth factor receptor. Journal of clinical oncology. 2004; 22:1201-1208.

42. Cooke T, Reeves J, Lanigan A, Stanton P. HER2 as a prognostic and predictive marker for breast cancer. Annals of oncology. 2001; 12 Suppl 1:S23-28.

43. Esposito C, Rachiglio AM, La Porta ML, Sacco A, Roma C, Iannaccone A, Tatangelo F, Forgione L, Pasquale R, Barbaro A, Botti G, Ciardiello F, Normanno N. The S492R EGFR ectodomain mutation is never detected in KRAS wild-type colorectal carcinoma before exposure to EGFR monoclonal antibodies. Cancer biology \& therapy. 2013; 14:1143-1146.

44. Tougeron D, Cortes U, Ferru A, Villalva C, Silvain C, Tourani JM, Levillain P, Karayan-Tapon L. Epidermal growth factor receptor (EGFR) and KRAS mutations during chemotherapy plus anti-EGFR monoclonal antibody treatment in metastatic colorectal cancer. Cancer chemotherapy and pharmacology. 2013; 72:397-403.

45. Faber K, Glatting KH, Mueller PJ, Risch A, HotzWagenblatt A. Genome-wide prediction of splice-modifying SNPs in human genes using a new analysis pipeline called AASsites. BMC bioinformatics. 2011; 12 Suppl 4:S2.

46. Zhang L, Yuan X, Chen Y, Du XJ, Yu S, Yang M. Role of EGFR SNPs in survival of advanced lung adenocarcinoma patients treated with Gefitinib. Gene. 2013; 517:60-64.

47. Tejpar S, Celik I, Schlichting M, Sartorius U, Bokemeyer C, Van Cutsem E. Association of KRAS G13D tumor mutations with outcome in patients with metastatic colorectal cancer treated with first-line chemotherapy with or without cetuximab. Journal of clinical oncology. 2012; 30:3570-3577.

48. Kumar SS, Price TJ, Mohyieldin O, Borg M, Townsend A, Hardingham JE. KRAS G13D Mutation and Sensitivity to Cetuximab or Panitumumab in a Colorectal Cancer Cell Line Model. Gastrointestinal cancer research. 2014; 7:23-26.

49. Mao C, Huang YF, Yang ZY, Zheng DY, Chen JZ, Tang JL. KRAS p.G13D mutation and codon 12 mutations are not created equal in predicting clinical outcomes of cetuximab in metastatic colorectal cancer: a systematic review and meta-analysis. Cancer. 2013; 119:714-721.

50. Douillard JY, Oliner KS, Siena S, Tabernero J, Burkes R, Barugel M, Humblet Y, Bodoky G, Cunningham D, Jassem J, Rivera F, Kocakova I, Ruff P, Blasinska-Morawiec M, Smakal M, Canon JL, et al. Panitumumab-FOLFOX4 treatment and RAS mutations in colorectal cancer. The New England journal of medicine. 2013; 369:1023-1034.

51. Fiskus W, Mitsiades N. B-Raf Inhibition in the Clinic: Present and Future. Annual review of medicine. 2016; 67:29-43.

52. Temraz S, Mukherji D, Shamseddine A. Dual Inhibition of MEK and PI3K Pathway in KRAS and BRAF Mutated Colorectal Cancers. International journal of molecular sciences. 2015; 16:22976-22988.

53. Backer JM. The regulation of class IA PI 3-kinases by intersubunit interactions. Current topics in microbiology and immunology. 2010; 346:87-114.

54. Mandelker D, Gabelli SB, Schmidt-Kittler O, Zhu J, Cheong I, Huang CH, Kinzler KW, Vogelstein B, Amzel LM. A frequent kinase domain mutation that changes the interaction between PI3Kalpha and the membrane. Proceedings of the National Academy of Sciences of the United States of America. 2009; 106:16996-17001.

55. Perrone F, Lampis A, Orsenigo M, Di Bartolomeo M, Gevorgyan A, Losa M, Frattini M, Riva C, Andreola S, Bajetta E, Bertario L, Leo E, Pierotti MA, Pilotti S. PI3KCA/PTEN deregulation contributes to impaired responses to cetuximab in metastatic colorectal cancer patients. Annals of oncology. 2009; 20:84-90.

56. Sartore-Bianchi A, Di Nicolantonio F, Nichelatti M, Molinari F, De Dosso S, Saletti P, Martini M, Cipani T, Marrapese G, Mazzucchelli L, Lamba S, Veronese S, Frattini M, Bardelli A, Siena S. Multi-determinants analysis of molecular alterations for predicting clinical benefit to EGFR-targeted monoclonal antibodies in colorectal cancer. PloS one. 2009; 4:e7287.

57. Williams CS, Bernard JK, Demory Beckler M, Almohazey D, Washington MK, Smith JJ, Frey MR. ERBB4 is overexpressed in human colon cancer and enhances cellular transformation. Carcinogenesis. 2015; 36:710-718.

58. De Bosscher K, Hill CS, Nicolas FJ. Molecular and functional consequences of Smad4 C-terminal missense 
mutations in colorectal tumour cells. The Biochemical journal. 2004; 379:209-216.

59. Fedor-Chaiken M, Hein PW, Stewart JC, Brackenbury R, Kinch MS. E-cadherin binding modulates EGF receptor activation. Cell communication \& adhesion. 2003; 10:105-118.

60. Pece S, Gutkind JS. Signaling from E-cadherins to the MAPK pathway by the recruitment and activation of epidermal growth factor receptors upon cell-cell contact formation. The Journal of biological chemistry. 2000; 275:41227-41233.

61. Witta SE, Gemmill RM, Hirsch FR, Coldren CD, Hedman K, Ravdel L, Helfrich B, Dziadziuszko R, Chan DC, Sugita M, Chan Z, Baron A, Franklin W, Drabkin HA, Girard L, Gazdar AF, et al. Restoring E-cadherin expression increases sensitivity to epidermal growth factor receptor inhibitors in lung cancer cell lines. Cancer research. 2006; 66:944-950.

62. Inge LJ, Barwe SP, D’Ambrosio J, Gopal J, Lu K, Ryazantsev S, Rajasekaran SA, Rajasekaran AK. Soluble E-cadherin promotes cell survival by activating epidermal growth factor receptor. Experimental cell research. 2011; 317:838-848.

63. Fichter CD, Timme S, Braun JA, Gudernatsch V, Schopflin A, Bogatyreva L, Geddert H, Faller G, Klimstra D, Tang L, Hauschke D, Werner M, Lassmann S. EGFR, HER2 and HER3 dimerization patterns guide targeted inhibition in two histotypes of esophageal cancer. International journal of cancer. 2014; 135:1517-1530.

64. Timme S, Ihde S, Fichter CD, Waehle V, Bogatyreva L, Atanasov K, Kohler I, Schopflin A, Geddert H, Faller G, Klimstra D, Tang L, Reinheckel T, Hauschke D, Busch H, Boerries M, et al. STAT3 expression, activity and functional consequences of STAT3 inhibition in esophageal squamous cell carcinomas and Barrett's adenocarcinomas. Oncogene. 2013. doi: 101038/onc2013298. 2013.

65. Berg KD, Glaser CL, Thompson RE, Hamilton SR, Griffin CA, Eshleman JR. Detection of microsatellite instability by fluorescence multiplex polymerase chain reaction. J Mol Diagn. 2000; 2:20-28.

66. Weisenberger DJ, Siegmund KD, Campan M, Young J, Long TI, Faasse MA, Kang GH, Widschwendter M, Weener D, Buchanan D, Koh H, Simms L, Barker M, Leggett B, Levine J, Kim M, et al. CpG island methylator phenotype underlies sporadic microsatellite instability and is tightly associated with BRAF mutation in colorectal cancer. Nature genetics. 2006; 38:787-793.

67. Zlobec I, Bihl M, Foerster A, Rufle A, Lugli A. Comprehensive analysis of $\mathrm{CpG}$ island methylator phenotype (CIMP)-high, -low, and -negative colorectal cancers based on protein marker expression and molecular features. The Journal of pathology. 2011; 225:336-343.

68. Berg M, Hagland HR, Soreide K. Comparison of $\mathrm{CpG}$ island methylator phenotype (CIMP) frequency in colon cancer using different probe- and gene-specific scoring alternatives on recommended multi-gene panels. PloS one. 2014; 9:e86657.

69. Kovaleva V, Geissler AL, Lutz L, Fritsch R, Makowiec F, Wiesemann S, Hopt UT, Passlick B, Werner M, Lassmann $\mathrm{S}$. Spatio-temporal mutation profiles of case-matched colorectal carcinomas and their metastases reveal unique de novo mutations in metachronous lung metastases by targeted next generation sequencing. Molecular cancer. 2016; 15:63.

70. Gerlach U, Kayser G, Walch A, Hopt U, Schulte-Monting J, Werner M, Lassmann S. Centrosome-, chromosomalpassenger- and cell-cycle-associated mRNAs are differentially regulated in the development of sporadic colorectal cancer. The Journal of pathology. 2006; 208:462-472.

71. Livak KJ, Schmittgen TD. Analysis of relative gene expression data using real-time quantitative PCR and the 2(-Delta Delta C(T)) Method. Methods. 2001; 25:402-408.

72. Tichopad A, Didier A, Pfaffl MW. Inhibition of real-time RT-PCR quantification due to tissue-specific contaminants. Molecular and cellular probes. 2004; 18:45-50. 